\title{
Private Label Line Proliferation and Private Label Tier Pricing: A New Dimension of Competition between Private Labels and National Brands
}

\begin{abstract}
In this study, we explore the impact of private label (PL) proliferation and pricing on consumer demand and derive profit implications for different scenarios: (i) dropping or adding a line (kids, health or muesli) within a PL tier and (ii) changing the PL tier prices. We use a representative household panel dataset (2008-2009) for the ready to eat (RTE) cereal category of two leading U.K. grocery retailers. Our results indicate line extension/delisting within the standard and premium PL tiers cannibalize each other and also steal business from NBs for the kids, healthy and muesli lines. Overall, premium PLs seem a profit generator tier that allows some room for further brand variant introductions within this tier. However, the retailer is better off, in terms of profits, if the proliferation within the economy PL tier is downgraded. Furthermore, both the retailer and NB manufacturers gain from an economy, standard and premium PL price increase, as it leads to a demand shift to NBs accompanied by a profit lift for the retailer.
\end{abstract}

Keywords: Private label tiers; Private label proliferation; Competition; Pricing; Demand model; Profit implications 


\section{Introduction}

One of the most salient changes in the grocery environment is the success of private labels (PLs). Since a large number of FMCG categories now already have at least one PL, retailers are increasingly adopting a multi-tiered PL strategy. In practice, this often means a switch from a single standard product offering to a three-tiered PL portfolio. This ranges from the typical cheap and low quality own labels (i.e., economy PLs) to somewhat less expensive PLs comparable in quality to the national brands (NBs) (i.e., standard PLs), to premium quality and high value added PLs (i.e., premium PLs) (Kumar and Steenkamp 2007). With this strategy retailers can satisfy the heterogeneous nature of consumers, and further create differentiation compared to their competitors (IRI 2016). For instance, Italian retailer Conad states that they grew in all channels primarily thanks to a multi-tier PL program, which they started a few years ago (Global Retail Mag 2013). Examples of retailers who launched a new economy or premium PL tier are international grocery chain 7Eleven (Just Food 2015) in U.S. and Korean retailer Lotte (IGD 2014). In the same spirit, recently an increasing number of leading retailers have extended their PL tier offerings with new alternatives targeted to distinct consumer segments (IPLG Europe 2014), such as health and kids lines (e.g. Good For You at U.K. retailer Asda and Conad Kids at Italian retailer Conad). Likewise, U.S. retailer Kroger has expanded its organic and healthy (standard and premium) PL lines recently (Market Watch 2012). In the meantime, industry observers increasingly state that economy PLs are facing big challenges. They are shrinking in volume sold since they fail to compete with discounters (IRI 2016). Moreover, they generate lower margins than standard PLs and most importantly they can cannibalize the current PL offerings that in the end leads category profit erosion (ter Braak et al. 2013; IPLG 2016). On the other hand, standard PL tier keeps its popularity and premium PLs is actually growing not only in size but also in value (IRI 2016). That brings us to evaluate what is the 
impact of this further proliferation within the tiers on consumer demand and retailer profits. In other words, whether new line introductions or delistings within different tiers help retailers. Together with this further proliferation in PL tier offerings, there is an ongoing discussion on how different PL tiers should be priced relative to each other and their NB competitors. The top retailers in U.K. (i.e. Tesco, Sainsbury's and Asda) have increased the price of economy PLs more than 40 per cent on average (Daily Mail 2012). Likewise, according to IRI, U.K. shopping basket data show that prices of standard PL items are slowly getting closer to NBs' prices (Just Food 2013; IRI 2016). Similarly, although industry observers advise the retailers to set their premium PLs price more than NB counterparts, there is still little known about how premium PLs should be priced (Millward Brown 2008 and World Trademark Review 2012).

Hence, this PL proliferation to new quality tiers (i.e. economy, standard and premium) and the further line proliferation within each tier pose challenges to a retailer's PL-NB portfolio management and price setting. Within a retailer, how do the different PL tiers/lines compete with each other and with the existing NBs in the assortment? And, how does this PL-NB competition influence consumer demand and retailer's profits? To answer these questions, we estimate a rich discrete choice demand model at the consumer level. The adopted approach allows us to derive demand and profit implications for different scenarios by calculating counterfactuals. More specifically, we derive the demand and profit effects under the following set of scenarios: (i) dropping or adding a line (kids, health or muesli) within a PL tier and (ii) changing the PL tier prices. By predicting consumer purchase adjustments to these changes in a retailer's PL-NB portfolio, we can define which PL/NB tiers and lines win or lose in terms of demand. Moreover, we derive what happens to a retailer's profits, addressing the recent call for more PL studies on profit implications (see Sethuraman and Gielens 2014). 
Insights on PL tiers in the academic literature are limited, as the majority of articles studying PLs do not make the distinction between different PL tiers. These studies regard PLs as one group (e.g. Lamey et al. 2012; Steenkamp and Geyskens 2014), or consider one specific tier (e.g. Pauwels and Srinivasan 2004). Nonetheless, ter Braak et al. (2014) study the category drivers of premium PL introduction. Among other things, they find that retailers are more likely to introduce premium PLs in categories with a more proliferated assortment in terms of standard PLs, still being aware of creating PL fatigue. Based on online experiments, Plameira and Thomas (2011) showed that consumers' quality perceptions of a premium PL increase in the presence of a value PL, whereas quality perceptions of a value PL are not affected by the presence of a premium PL alternative. In addition, Geyskens and colleagues (2010) show that, based on a brand-choice model with context effects, the introduction of an economy PL cannibalizes the incumbent standard PL but benefits the mainstream NBs. Similarly, an introduction of a premium PL cannibalizes the incumbent PLs (i.e. budget and standard) and sometimes benefits premium-quality NBs. Gielens (2012) studies the impact of PL and NB introductions on category sales and the share of the top-3 NBs and the three PL tiers (aggregated over brand variants). She finds, among other things, that new products introduced by standard PLs and premium PLs are sometimes able to boost category sales, to shrink NB rivals' shares, and to cannibalize other PL tiers (respectively, economy and premium, and only economy), whereas new products introduced under the economy PL flag only stimulates overall economy PL share. We contribute to this literature stream in multiple ways. To the best of our knowledge, we are the first to study the demand implications of (i) further line proliferation within PL tiers (rather than PL tier introductions (see Geykens et al. $2010^{1}$ \& Palmeira and Thomas 2011)

\footnotetext{
${ }^{1}$ Compared to Geyskens et al. (2010), we consider a lower level of aggregation in our demand model, where we only aggregate across different product sizes but not brand variants (i.e. different formulation, taste, ...). This allows us to study the introduction and delisting of PL lines within each PL tier. Second, our model allows consumers' price sensitivity to differ not only between consumers but also between brand types (i.e. NB vs. PL), quality tiers (i.e. low,
} 
- or new product introductions within a PL tier (see Gielens 2012)) and (ii) different PL tier price

settings. Finally, besides the demand implications of further proliferation and price decisions within the multi-tier PL strategy, we study the profit implications for the retailer.

In sum, the study aims to answer the following research questions: How do PL lines/ tiers and NBs compete within a retailer? What are the demand and profit implications of this competition for the retailer? The rest of the paper is organized as follows. In the next section, we provide a brief overview of the data, followed by a section that presents the empirical framework with more detail regarding the method of estimation. In section 4, we present the empirical results. In section 5 , what-if scenarios are discussed in detail. Finally, we conclude with discussion, limitations and ideas for further research in section 6 .

\section{Data}

\section{Research Context}

To study the competition between PLs and NBs, we obtained U.K. household panel data from Kantar Worldpanel through AiMark. This panel data consists of purchase records of a representative set of 2,353 U.K. households that shop in the ready to eat cereal (RTE) cereal category for the period between January 1, 2008 and 31 December, 2009.

The U.K. has one of the strongest PL presences in Europe and is considered as the most advanced and sophisticated PL country globally with a (volume) market share of over 45\% (IRI 2015; PLMA 2016). One of the most distinctive features of the U.K. grocery market is that PLs

medium and high) and lines (i.e. kids, health), allowing us to better capture the implications of price changes. In addition, Geyksens et al. (2010) ignore the observations in which no purchase occurs in the category at the retailer, which is problematic due to informative-missingness (Chib, Seetharaman and Strijnev 2004). As such, our model is extended with an outside good option that captures the consumers' decision to purchase in the category at another retailer, and thus allows consumers to switch to offerings of competing retailers in response to an assortment or price changes at the focal retailer (Chintagunta, Bonfrer and Song 2002), which again results in more realistic substitution patterns. Finally, whereas Geyskens et al. (2010) study demand shifts due to an introduction of an economy and premium PL tier over time (going from 1993 to 2006), our study studies consumer demand in a setting where all three PL tiers and its lines are already well-established in the market (i.e. 2008-2009). 
present in virtually every product category for several decades (Burt 2000). Hence, in our estimation window, the U.K. Market is already a mature PL market where all the brand introductions were made several years ago and consumers are well aware of the three PL tiers and theirs line extensions. According to industry observers, many countries are headed towards the U.K. model (Cotterill 1997), which makes our time window representative for other countries moving slower in their PL lines development. In our observation period, economy, standard and premium PLs cover respectively $2.96 \%, 23.64 \%$ and $.27 \%$ of the RTE cereal volume sales across all retailers. The outstanding success of PLs in the U.K. can largely be attributed to the fact that $74 \%$ of the retail grocery market is held by the top four retailers (The Guardian 2013). Indeed, the empirical literature and the industry findings show that the level of concentration in the retail market is directly related to the market share of PLs in total retail sales (Bozhinova 2014; Tarziján 2003; Nielsen 2014). High concentration in grocery retailing is the key factor behind the high market share of PLs in UK (PWC 2011). Hence the current PL market structure, where these multi-tiered PL offerings are pioneered (Kumar and Steenkamp 2007) makes U.K. an interesting place to study.

In our analysis, we focus on two of the three largest retailers in the U.K. grocery market, namely Asda and Sainsbury's. Asda (Sainsbury's) is the second (third) largest retailer in the U.K. grocery market with 525 (597) stores and a market share of 17.1 (16.4\%) in 2016 (Asda Supplier 2016; J Sainsbury plc 2016). Both retailers offer a popular PL assortment fitting into the 3-tier ranging strategy: 'Good' (i.e. (Asda's) Smart Price, Sainsbury's Basics), 'Better' (i.e. (Asda's) Chosen by You, Sainsbury's) and 'Best' (i.e. (Asda's) Extra Special, (Sainsbury's) Taste the Difference), accounting for $45.8 \%$ at Asda and $50.8 \%$ at Sainsbury's of total volume sales (The Grocer 2014).

To answer our research questions, we obtained data for the RTE cereal category. The RTE 
cereal category is a large, mature category for both PLS and NBs, where more than $40 \%$ of U.K. consumers regularly buy PLs (YouGov 2013). The RTE cereal category consists of a large number of brand variants (e.g. honey, chocolate, blueberry) grouped within multiple lines ${ }^{2}$ (e.g. kids, health, muesli) of several PLs and NBs in the different quality tiers, making it a perfect category to study the competition between PLs and NBs across tiers, lines and brand variants. Importantly, no rebrandings of PLs and NBs, or major PL or NB entries or exits occurred in our two year observation period.

\section{Level of Aggregation}

The majority of marketing studies aggregate SKU's at the brand level (see for instance Geyskens et al. 2010, Horsky et al. 2012 and Gordon et al. 2013). In our research setting, where we focus on brand variants to derive competition, this would lead to an aggregation bias. In fact, SKU's in the RTE cereal category varies in terms of size, flavor and main ingredient (i.e. corn, barley, oat). But, even more importantly, each SKU (irrespective of size) of the same brand considerably varies in terms of its pricing. Therefore, we only aggregate SKUs across sizes and not across brand variants, and call it "brand variant". 3

In line with Empen et al. (2011), we select for each retailer all brand variants with a volume share above $0.5 \% .^{4}$ This results in 63 (57) selected brand variants at Asda (Sainsbury's) which belong to four NB mother brands, namely Kellogg's, Nestle and Weetabix, Quaker and all PL tiers, accounting for 79 (82\%) of the RTE cereal category volume sales at Asda (Sainsbury's).

\footnotetext{
${ }^{2}$ Some brand variants are classified to more than one line. In Sainsbury's, $7 \%$ of the brand variants are classified as both muesli and healthy cereal. In Asda, we don't see such overlapping.

${ }^{3}$ For instance, under the mother brand flag Kellogg's, Kellogg's Special K brand offers the following brand variants among others: Kellogg's Special K (regular), Kellogg's Special K Red Fruit, Kellogg's Special K Yogurt, where the different package sizes (e.g. Kellogg's Special K Red Fruit 500g and 300g) are aggregated within a brand variant.

${ }^{4}$ For the premium PL tier, we relaxed this rule and include all PL brands (and its corresponding brand variants) where the combined market share of all brand variants is above $0.5 \%$, in order to include sufficient PL premium alternatives in our analysis.
} 
We adopt the expert-based classification used by Geyskens et al. (2010) to group each brand variant into a quality tier, i.e. low, medium or high. Taking into account the brand type (i.e. NB vs. PL), this results in five groups: mainstream $N B$ (medium quality, i.e. Nestlé \& Weetabix), premium $N B$ (high quality; i.e. Kellogg's), economy PL (low quality; i.e. Sainsbury’s Basics), standard PL (medium quality) and premium PL (high quality). Table 1 gives an overview of the average price paid, market share and level of proliferation for each group and each retailer. Overall, the economy PLs are standing at the bottom-of-the-market as a lowest priced option, followed by the standard PLs and subsequently premium PLs are positioned close to NBs, which is in line with Kumar and Steenkamp (2007). The number of brand variants and SKUs are comparable for standard PL, mainstream NB and premium NBs, while it is considerably lower for economy and premium PLs. At both retailers PLs have a combined (volume) market share above $40 \%$ (i.e. $47.7 \%$ at Asda and 44\% at Sainsbury's). Despite these overall similarities, the chosen PL price strategy clearly differs between both retailers. The price gaps between the different PL tiers at Asda are much smaller than at Sainsbury's, whereas the Sainsbury's PL tier prices cover a much broader spectrum going from 0.87 for their economy PLs to 2.87 for the premium PLs compared to 1.00 and 2.41 , respectively, at Asda. In addition, the Asda assortment is more proliferated in terms of the number of SKUs. The only exception is the premium tier, where Asda only offers 3 cereal alternatives compared to 27 at Sainsbury's.

Table 1: Summary statistics

\begin{tabular}{c|cc|cc|ccc|cc}
\hline & \multicolumn{2}{c}{$\begin{array}{c}\text { Mean Price } \\
\text { (price per kilo) }\end{array}$} & \multicolumn{2}{c}{$\begin{array}{c}\text { Market Share } \\
\text { (volume) }\end{array}$} & \multicolumn{2}{c}{ \# Brand Variants } & \multicolumn{2}{c}{ \# SKUs } \\
& Sainsbury's & Asda & \multicolumn{1}{c}{ Sainsbury's } & Asda & \multicolumn{1}{c}{ Sainsbury's } & Asda & Sainsbury's & Asda \\
\hline Economy PL & 0.87 & 1 & $4.23 \%$ & $7.00 \%$ & 4 & 8 & 20 & 46 \\
Standard PL & 1.98 & 2.06 & $34.02 \%$ & $40.40 \%$ & 15 & 23 & 145 & 283 \\
Premium PL & 2.87 & 2.41 & $6.15 \%$ & $0.30 \%$ & 6 & 2 & 27 & 3 \\
Mainstream NB & 3.54 & 3.63 & $27.48 \%$ & $21.60 \%$ & 20 & 15 & 146 & 189 \\
Premium NB & 3.7 & 3.45 & $28.12 \%$ & $30.60 \%$ & 12 & 12 & 144 & 225 \\
\hline
\end{tabular}


We further classify each brand variant in lines. More specifically, we distinguish brand variants into kids, health, muesli and regular RTE cereal lines. Brand variants are classified as a "kids" line alternative if the product package carries a picture of a cartoon or another kids friendly image (Ulger, 2008). Cereals based on raw rolled oats and other ingredients including grains, fresh or dried fruits, seeds and nuts, are classified as "muesli" cereals. To determine whether the alternative is healthy or not, we check whether brand variants are advertised as a healthy cereal with a specific name/range (e.g. Kellogg's Red Berry Special K, Sainsbury's Be Good To Yourself range) and/or whether they are emphasizing the health on its packaging (e.g. 'good source of fiber' or 'made with wholegrain').

\section{Household Selection}

In line with Seetharaman (2004) and Geyskens et al. (2010), we exclude households that did not purchase one of the selected brand variants at least four times per year, on average, as well as households for which the selected brand variants did not represent minimum $70 \%$ of their yearly category purchases at the retailer.

\section{Methodology}

\section{Demand Model}

To answer our research questions, we apply a rich random coefficients logit model for the RTE category for each retailer. The indirect latent utility of household $i$ from buying brand variant $j$ during weekly shopping trip $t$ at the retailer is given by ${ }^{5}$ :

\footnotetext{
${ }^{5}$ For some households in certain weeks, multiple shopping trips within a week are observed, which is the case for $40.75 \%$ of the observed shopping trips. In this case we only selected the first shopping trip of the specific week for analysis. However, the same substantive findings are obtained (i) if we allow for daily instead of weekly shopping trips, or (ii) if these multiple weekly observations for a household are retained by using different household id's for each additional shopping trip with a week but with identical household characteristics. In addition, some households buy multiple brand variants at the same weekly shopping trip, which is the case for 22,38\% of the observed shopping trips. For the sake of simplicity, we only included the first brand variant registered in the panel dataset for that household at
} 


$$
U_{i j t}=\gamma_{i j}+\beta_{i} X_{j t}+\alpha_{i} p_{j t}+\theta_{i} I_{i j t}+\xi_{j t}+\epsilon_{i j t}
$$

where $\gamma_{i j}$ denotes a household $i$ 's valuation for brand variant $j$ (relative to the base option which is outside good). The assortment variable $X_{j t}{ }^{6}$ quantifies the number of SKU's available for brand variant $j$, and $\beta_{i}$ captures a household $i$ 's valuation with respect to the assortment variable. Furthermore, $p_{j t}$ is average price paid across all households for brand variant $j$ at week $t$, converted in real terms using the yearly U.K. consumer price index obtained from the Office for National Statistics in the U.K., and $\alpha_{i}$ is a household-specific valuation of price. $I_{i j t}$ denotes a dynamic loyalty variable, suggested by Guadagni and Little (2008) and specified as:

$$
I_{i j t}=\lambda I_{i j t-1}+(1-\lambda) \text { LastPurchase }_{i j t}
$$

where LastPurchase ${ }_{i j t}$ is a dummy variable equal to 1 when brand variant $j$ was last purchased at the retailer, and 0 otherwise, $\lambda$ is a smoothing constant between 0 and $1^{7}$ (see Melis et al. 2015 for a similar practice). Hence, the parameter $\theta_{i}$ captures a household's "loyalty" or "switching cost" of moving from one brand variant to another (Gordon et al. 2013; Guadagni and Little 2008). Unobserved brand variant characteristics, $\xi_{j t}$, may include brand variant image, quality and assigned shelf space. Finally, $\epsilon_{i j t}$ is a household $i$ specific valuation for brand variant $j$ in week $t$ i.e. the "logit error term". It is identically and independently distributed across brand variants according to the Type I extreme value distribution.

In order for our model to yield plausible and realistic substitution patterns among the brand variants offered by the focal retailer, it is necessary to include an "outside good" option (Nevo 2001). In our research setting, the outside good option $(j=0)$ for the brand-variant choice decision

the specific at Sainsbury's. However, similar findings are obtained if we randomly select a brand variant out of all brand variants bought by a household at a specific shopping trip.

${ }^{6}$ The competitive effects such as the assortment depth of other PL tiers and NB tiers are not directly enter the utility in Equation (1). However, they affect the choice probabilities.

${ }^{7}$ In line with prior research (Spotts 2014; Gupta 1988 and Kalwani et al. 1990), the smoothing constant is set equal to 0.7. Still, the same substantive findings are obtained for alternative smoothing constants $(0.6,0.75$ and 0.87$)$. 
is to purchase cereal from any other grocery retailer in the U.K. market. Without incorporating the existence of an outside good option, a simultaneous increase in the price of all brand variants offered by our focal retailer would result in no change in total consumption at the retailer. This would ignore the fact that consumers are able to buy their cereals at competing retailers.

We consider a specification that allows for both observed and unobserved household heterogeneity regarding the valuations of alternatives. The alternative $j$ evaluations, $\gamma_{i j}$, and the price sensitivity, $\alpha_{i}$, may depend on both observed household characteristics and unobserved heterogeneity. Based prior literature and data availability, we include the following observed household characteristics: Number of Children ${ }_{i}$, Social Class $_{i}$ (i.e. lower versus middle versus upper), Average Buying Frequency $y_{i}$ and Share of Wallet $_{i}$. Average Buying Frequency ${ }_{i}$ denotes how many times on average a household shops for cereal at Sainsbury's during a 4 week time window (Bodapati and Gupta 2005). Share of Wallet ${ }_{i}$ represents the household's average spending on cereal in the focal retailer relative to all other U.K. retailers (Ailawadi et al. 2008; Gordon et al. 2013). Unobserved heterogeneity is incorporated through a random coefficient approach.

With regard to the valuations for the different alternatives, we specify two terms: one for the outside good (3) and one for the brand variants (4):

$$
\begin{array}{r}
\gamma_{i 0}=\gamma_{0}^{0}+\gamma_{0}^{\sigma} v_{i}^{r} \quad v_{i} \sim N(0,1) \\
\gamma_{i j}=\gamma_{j}^{0}+\sum_{h} \sum_{p} \gamma^{h p} H_{\text {Hchar }} * P G d u m m y_{p}
\end{array}
$$

where $\gamma_{j}^{0}$ captures the means of the distributions of heterogeneity across households with respect to intrinsic brand variant $j$ preferences. In order to capture the observed heterogeneity for the valuation of product group dummy variables, we interact product group dummies (PGdummy $)_{p}$ with household characteristics $H H_{c h a r}$, where $p$ is an index for the product groups and $h i$ is an index 
for observed household characteristics. ${ }^{8}, 9$

With regard to the valuation of price, we specify the price coefficient as:

$$
\alpha_{i}=\alpha^{0}+\sum_{h} \alpha^{h} H H_{c h a r}+\alpha^{\sigma} v_{i}^{r} \quad v_{i} \sim N(0,1)
$$

where $\alpha^{0}$ is the mean responsiveness to the price, common across households. To account for observed heterogeneity, we interact price with the above mentioned observed household characteristics $\mathrm{HHChar}_{h i}$. To account for unobserved heterogeneity, we use a random coefficient specification for price (Chintagunta et al. 2002). Here, $\alpha^{\sigma}$ is the standard deviation around the mean valuation of price and $v_{i}$ is a random draw from the standard normal distribution, capturing unobserved household heterogeneity regarding price ${ }^{10}$.

\section{Estimation}

Based on the model assumptions, the probability that household $i$ with unobservable characteristic vector $v_{i}$ chooses the brand variant $j$ that maximizes utility among all the available alternatives is given by:

$$
\operatorname{Pr}_{i j}\left(v_{i}\right)=\frac{\exp \left(\gamma_{i j}+\beta_{i} X_{j t}+\alpha_{i} p_{j t}+\theta_{i} I_{i j t}+\xi_{j t}\right)}{1+\sum_{k=1}^{J} \exp \left(\gamma_{i k}+\beta_{i} X_{k t}+\alpha_{i} p_{k t}+\theta_{i} I_{i k t}+\xi_{j t}\right)}
$$

These choice probabilities can be integrated over the unobserved and normally distributed term $v_{i}$, to obtain average choice probabilities for each household. We then estimate the model with simulated maximum likelihood as in Chintagunta and Dube (2005) and Train (2003). To approximate the integral in the choice probability, we take 100 draws for $v_{i}$ from the standard

\footnotetext{
${ }^{8}$ The product group dummies refers to both (i) line dummies (i.e. kids, muesli and health) and (ii) group dummies (i.e. brand type vs. quality tiers) (i.e. economy PL, standard PL, premium PL, mainstream NB and premium NB).

${ }^{9}$ The mean valuation of the product group dummies were dropped from the model due to multicollinearity problems as individual brand variant dummies are also included in the model.

${ }^{10}$ In the special case where $\alpha^{\sigma}=0$, there is no unobserved heterogeneity and we would obtain the conditional logit model.
} 
normal distribution (see Appendix for the details).

\section{Counterfactuals}

To conduct our counterfactuals, we compute diversion ratios to compute how closely brand variants and product groups compete with each other; and its corresponding profit implications.

Diversion ratio. A diversion ratio quantifies the proportion of demand captured by the different alternatives in the market when price of one of the alternatives is changed (see Kelchtermans and Verboven (2007) and Conlon and Mortimer (2013) for an in-depth discussion). A practical advantage of the diversion ratio is that it is a unit free measure, which captures the relative degree of competition between products very well. As such, it gives similar magnitudes when one considers substitution responses to small or larger price changes, or to an entire product elimination. We consider here the effect of an elimination of all brand variants in group $\delta_{1}$ (i.e. dropping a tier) from the retailer's assortment, which is the special case where the prices in the group become infinitely large. In this case, $D R_{\delta_{1} \delta_{2}}$ measures the fraction of demand lost from the eliminated group $\delta_{1}$ that flows back to the group $\delta_{2}$.

$$
D R_{\delta_{1} \delta_{2}}=\frac{\sum_{i} \sum_{k \in \delta_{2}}\left(s_{i k}\left(\boldsymbol{p}^{\mathbf{1}}\right)-s_{i k}\left(\boldsymbol{p}^{\mathbf{0}}\right)\right)}{\sum_{i} \sum_{j \in \delta_{1}} s_{i j}\left(\boldsymbol{p}^{\mathbf{0}}\right)}
$$

The initial price vector $\boldsymbol{p}^{\mathbf{0}}$ consists of the current prices of all brand variants, and the new price vector $\boldsymbol{p}^{\mathbf{1}}$ sets the price to infinity for the eliminated brands $j$ in the group $\delta_{1}$. For example, to capture the demand implications of a PL tier line delisting, the prices of all brand variants within this PL tier line are replaced with a very high price (such that its demand $s_{j}\left(\boldsymbol{p}^{\mathbf{1}}\right)$ becomes zero where $\left.s_{j}\left(\boldsymbol{p}^{\mathbf{1}}\right)=\sum_{i} s_{i j}\left(\boldsymbol{p}^{\mathbf{1}}\right)\right)$ while keeping the prices of the other brand variants at the same level in the new price vector. The diversion ratios measure the percentage of PL tier line demand that goes to each brand variant. Similarly, to capture the demand implications of an introduction of a PL tier 
line, we generate a hypothetical price level, assortment level and loyalty value for all new brand variants within this PL tier line ${ }^{11}$. Note that the diversion ratio formula (7) is a special case of a finite price increase for the products in group $\delta_{1} .{ }^{12} \mathrm{We}$ finally point out that the concept of the diversion ratio is closely related to own- and cross-price elasticities ${ }^{13}$ (see e.g. Werden (1998)). In both cases, the prices of rival products are kept fixed; in profit counterfactuals, one can allow prices of rivals to respond.

Profit. We also consider the profit incentives for eliminating (i) a group of brand variants, and (ii) changing the price gap between PL tiers and NB tiers. In order to calculate the net effects on category profit, we supplement our data with the external margin information ${ }^{14} m_{j}^{0}=\left(p_{j}^{0}-c_{j}\right) / p_{j}^{0}$ that allows us to derive wholesale price $c_{j}$. For PL tiers, we obtained average margin data per brand type \& tier for our focal category (i.e. RTE cereal) from AiMark (for a comparable retailer in the Dutch market) together with the accompanying standard deviation. Retailers' percentage profit margins $m_{j}^{0}$ are $21.6 \%$ for economy PLs, $34.5 \%$ for standard PLs and $28.3 \%$ for premium PLs on average. Similarly, for NBs, it is $20 \%$. Suppose that there is a price increase of all brands $j$ in group $\delta_{1}$ (either a finite price increase, or an infinite increase in case the product is eliminated). The change in profits from such a price increase or delisting of the brand variants in group $\delta_{1}$ is as

${ }^{11}$ For instance, to construct the prices of newly introduced economy PL kids alternatives, first we calculate the ratio between standard PL regular and standard PL kids alternatives, Then, multiply this ratio with economy PL regular alternatives to construct economy PL kids prices.

${ }^{12}$ In the more general case of a finite price change of the alternatives in a group, the relevant formula for the diversion ratio is: $D R_{\delta_{1} \delta_{2}}=-\frac{\sum_{i} \Sigma_{k \in \delta_{2}}\left(s_{i k}\left(\boldsymbol{p}^{\mathbf{1}}\right)-s_{i k}\left(\boldsymbol{p}^{\mathbf{0}}\right)\right)}{\sum_{i} \Sigma_{j \in \delta_{1}}\left(s_{i j}\left(\boldsymbol{p}^{\mathbf{1}}\right)-s_{i j}\left(\boldsymbol{p}^{\mathbf{0}}\right)\right)}$. If we eliminate the entire group (by setting the $\left.p_{j}=\infty\right)$, then $s_{j}\left(\boldsymbol{p}^{\mathbf{1}}\right)=$ $\sum_{i 3} s_{i j}\left(\boldsymbol{p}^{\mathbf{1}}\right)=0$, so that we obtain (7).

${ }^{13}$ If we denote the own-price elasticity of product $\mathrm{A}$ by $\varepsilon_{A}$ and the cross-price elasticity of product B's demand with respect to A's price by $\varepsilon_{B A}$ ), then the diversion ratio becomes the following:

$$
\Delta q_{B} / \Delta q_{A}=\left(\varepsilon_{B A} q_{B}\right) /\left(-\varepsilon_{A} q_{A}\right)
$$

This can be interpreted as the ratio of the cross-price over the own-price elasticity, multiplied by the demand ratio of $\mathrm{A}$ and $\mathrm{B}$.

${ }^{14}$ Following the example of Allenby and Rossi (1991), the retailer who seeks to apply this method to solve his pricing problem will have access to accurate cost data. 
follows:

$$
\begin{gathered}
\Delta \pi=\sum_{j \epsilon \delta_{1}} \underbrace{\left.\pi_{j}\left(\boldsymbol{p}^{\mathbf{1}}\right)-\pi_{j}\left(\boldsymbol{p}^{\mathbf{0}}\right)\right)}_{\begin{array}{c}
\text { Change in profit } \\
\text { affected products }
\end{array}}+\sum_{j^{\prime} \epsilon \delta_{1}}(\underbrace{\left.\pi_{j^{\prime}}\left(\boldsymbol{p}^{\mathbf{1}}\right)-\pi_{j^{\prime}}\left(\boldsymbol{p}^{\mathbf{0}}\right)\right)}_{\begin{array}{c}
\text { Change in profit } \\
\text { remaining products }
\end{array}} \\
=\sum_{j \in \delta_{1}}\left[\left(p_{j}^{1}-c_{j}\right) s_{j}\left(\boldsymbol{p}^{\mathbf{1}}\right)-\left(p_{j}^{0}-c_{j}\right) s_{j}\left(p^{0}\right)\right] \\
+\sum_{j^{\prime} \epsilon \delta_{1}}\left[\left(p_{j^{\prime}}^{1}-c_{j^{\prime}}\right) s_{j^{\prime}}\left(\boldsymbol{p}^{\mathbf{1}}\right)-\left(p_{j^{\prime}}^{0}-c_{j^{\prime}}\right) s_{j^{\prime}}\left(\boldsymbol{p}^{\mathbf{0}}\right)\right] \\
\text { where } \quad s_{j}(p)=\sum_{i} s_{i j}(p) \text { and } s_{j^{\prime}}(p)=\sum_{i} s_{i j^{\prime}}(p)
\end{gathered}
$$

This can be written as:

$$
\begin{gathered}
\Delta \pi=\sum_{j \in \delta_{1}} \underbrace{\left[\left(p_{j}^{1}-p_{j}^{0}\right) s_{j}\left(\boldsymbol{p}^{\mathbf{1}}\right)\right.}_{\text {direct price effect }}+\underbrace{\left.m_{j}^{0} p_{j}^{0}\left(s_{j}\left(\boldsymbol{p}^{\mathbf{1}}\right)-s_{j}\left(\boldsymbol{p}^{\mathbf{0}}\right)\right)\right]}_{\begin{array}{c}
\text { reduced sales effect } \\
\text { for affected alternatives }
\end{array}} \\
+\sum_{j^{\prime} \epsilon \delta_{1}}^{\sum_{\begin{array}{c}
\text { increased sales effects } \\
\text { for remaining alternatives }
\end{array}}^{m_{j^{\prime}}^{0} p_{j^{\prime}}^{0}\left(s_{j^{\prime}}\left(\boldsymbol{p}^{\mathbf{1}}\right)-s_{j^{\prime}}\left(\boldsymbol{p}^{\mathbf{0}}\right)\right)}} \\
\text { where } m_{j}^{0}=\frac{p_{j}^{0}-c_{j}}{p_{j}^{0}} \text { and } m_{j^{\prime}}^{0}=\frac{p_{j^{\prime}-c_{j^{\prime}}}^{p_{j^{\prime}}^{0}}}{}
\end{gathered}
$$

According to equation 11, the profit effect of a price increase or an entire delisting consists of three terms. The first term captures the direct profit effect from the price increase on the category profit. This term will be zero under an entire elimination of the group (since then $\boldsymbol{p}^{\mathbf{1}}$ is sufficiently large so that $s_{j}\left(\boldsymbol{p}^{\mathbf{1}}\right)=0$ ). The second term captures the negative effect on category profits from the reduced sales of the products in group $\delta_{1}$. Finally, the last term captures the substitution effect, i.e. the positive effect on profits from the increased sales of the other alternatives.

The above discussion considered the profit impact of a price increase or delisting, holding 
the rival prices fixed. In practice, one can also consider the profit impact when the rivals respond. As a robustness analysis we consider counterfactuals where rivals respond by half of the initiated price increase. This avoids a full equilibrium analysis, which would in any case have to rely on various assumptions such as the complicated manufacturer-retailer relationship.

\section{Empirical Results}

\section{Parameter Estimates}

The parameter estimates of our two demand models are presented in Table 2 and 3. The negative price coefficient (Asda:-0.982; $\mathrm{p}<.01$; Sainsbury's:-1.081; $<<.01)^{15}$, indicates that households are overall price sensitive. Still, there is sufficient heterogeneity both observed, as illustrated by the significant interactions with the household characteristics, and unobserved (Asda: $\mathrm{SD}=0.614 ; \mathrm{p}<.01$; Sainsbury's: $\mathrm{SD}=0.534 ; \mathrm{p}<.01$ ), as has also been reported in previous literature (Meza and Sudhir 2010). Also, consumer heterogeneity regarding the valuation of the inside goods relative to the outside good is observed (Asda: $\mathrm{SD}=3.024 ; \mathrm{p}<.01$; Sainsbury's: $\mathrm{SD}=2.888 ; \mathrm{p}<.01$ ). On average, the significant random coefficient for the outside good dummy variable indicates that substitution between inside goods (current retailer's offerings) is stronger than substitution towards the outside good (other retailers' offerings) (Asda: 7.479; $\mathrm{p}<.01$; Sainsbury’s: 7.513; $\mathrm{p}<.01$ ). Furthermore, the more $S K U s$ a retailer offers within a brand variant, the more likely households are to choose the brand variant (Asda: 0.062; p<.01; Sainsbury's: 0.085; p<.01) (see Tan and Cadeaux 2011 for

\footnotetext{
${ }^{15}$ Although we include a full set of brand variant fixed effects, price $\left(p_{j t}\right)$ might be correlated with unobserved changes in brand variant characteristics. To assess this possible endogeneity, we adopt the control function approach (Petrin and Train 2010). We use two sets of instruments: (i) weekly commodity price indexes for the main ingredients of RTE cereal, namely wheat, barley, oat and sugar, collected by the Department for Environment, Food and Rural Affairs U.K. interacted with brand variant dummies, as each brand variant has a different composition of main ingredients and (ii) the price of the same brand variant at the focal retailer in the previous week $\left(p_{j t-1}\right)$ (see Villas-Boas and Winer 1999 for a conceptually similar practice). All auxiliary regressions showed acceptable levels for $\mathrm{R}^{2}(>95 \%)$. For both retailers, we find that the parameter estimates, and in particular the price coefficient, remain very similar after accounting for the correction term for both sets of instruments. This suggests that our specification already accounts well for unobserved brand variant characteristics and the role of time-varying unobservables is limited.
} 
similar insights). Similarly, the significant positive brand-variant loyalty coefficient (Asda: 11.650; $\mathrm{p}<.01$; Sainsbury's: $11.930 ; \mathrm{p}<.01)$ reveals that due to state dependence, a brand variant has a higher probability of being purchased if a brand variant has been bought on previous purchase occasions, supporting prior work (Pauwels et al. 2002 and Geyskens et al. 2010).

With regard to the brand type*quality tier dummies (relative to outside good option) interacted with the household characteristics, substantial heterogeneity across households is observed. For instance, households that belong to a low social class (Asda: 0.538; p<.01; Sainsbury's: $0.973 ; \mathrm{p}<.01$ ) and households that spend a larger portion of their cereal budget at the retailer are more likely to purchase economy PL options (Asda: 4.333; p<.01; Sainsbury's: 3.015; $\mathrm{p}<.01$ ). Standard PLs are less appealing for households with children (Asda: -0.362; $\mathrm{p}<.01$; Sainsbury's: $-0.268 ; \mathrm{p}<.01$ ), and households' probability of choosing standard PLs increases if their spending portion of their budget at the retailer increases (Asda: 4.526; p<.01; Sainsbury's: 3.652; $\mathrm{p}<.01$ ). Although Geyskens et al. (2010) find that the premium PL appeal is not related to household socio-demographics, we find that premium PLs are less appreciated by households with children (Asda: -0.627 ; $<$ <.01; Sainsbury's:-0.466; $\mathrm{p}<.01$ ) and are bought by more loyal households (Asda: 3.872; $\mathrm{p}<0.01$; Sainsbury's: 3.445; $\mathrm{p}<0.01)$.

With regard to the line dummies (i.e. kids, muesli and health) interacted with household characteristics, again significant observed heterogeneity is observed. Among others, the number of children has a negative effect on the probability of choosing health (Asda: $-0.206 ; \mathrm{p}<.01$; Sainsbury's: $-0.220 ; \mathrm{p}<.01$ and muesli lines (Asda: -0.157; $\mathrm{p}<.01$; Sainsbury's:-0.137; $\mathrm{p}<.01$ ), but the opposite effect for kids alternatives (Asda: 0.278; $\mathrm{p}<.01$; Sainsbury's: 0.327 ; $<.01$ ) which is in line with Nevo (2001). Furthermore, households that belong to low class tend to be less likely to buy healthy alternatives (Asda: -0.127 ; $<.01$; Sainsbury's: $-0.128 ; \mathrm{p}<.01$ ). In contrast, low class 
households are more likely to choose kids brand variants (Asda: 0.340; p<.01; Sainsbury's: 0.129; $\mathrm{p}<.05)$. Similarly, household who are more frequently buying cereals at the specific retailer tend to be less likely to purchase healthy (Asda: $-0.027 ; \mathrm{p}<.01$; Sainsbury's: $-0.015 ; \mathrm{p}<.05$ ) cereals. Also, the probability of choosing healthy cereals decreases as households' share of wallet increases for Sainsbury's $-0.177 ; \mathrm{p}<.01)$. However, we find that healthy alternatives in Asda are more appreciated if the households' become more loyal to Asda (Asda: 0.274; $\mathrm{p}<.01$ ).

In sum, these findings indicate the importance of accounting for both observed and unobserved consumer heterogeneity, in particular regarding the valuation of the price and importance of including both line and brand type*tier dummies. Accounting for this type of heterogeneity results in more flexible substitution patterns and a first indication that substitution is also driven by quality tier, brand types and attributes. We will explore this in much more detail in our counterfactuals in the next subsection.

\section{What-if scenarios}

\section{Elimination/introduction of a line within a PL Tier}

Here, we explore the demand and profit implications of adding or dropping (i) a kids line, (ii) a health line; and (iii) a muesli line for each PL tier. To disentangle who wins or loses, we compare the inside diversion ratios derived from our rich model with observed and unobserved household heterogeneity with the "fair share" derived from a simplified model without any household heterogeneity (benchmark setting) (see Table A-1 in Appendix). The fair share or benchmark share therefore captures the expected changes in market share if the demand of the removed (introduced) PL line variant shifts proportionally to (from) each incumbent. A diversion ratio relative higher (lower) than the fair share indicates that the tier/line/brand variant wins relatively more (less) 
demand ${ }^{16}$.

Kids line. First, when the kids PL line from the standard PL tier is eliminated (see Table A-1 in Appendix), its share is mainly absorbed by the outside good (Asda: $24.30 \%$; Sainsbury's: 26.2\%), followed closely by standard PL non-kids (Asda: 18.33; Sainsbury's: 18.70\%) and mainstream NB non-kids (Asda: 18.8\%; Sainsbury's: 21.8\%) options. However, a comparison with the benchmark setting shows that all remaining kids options benefit from this elimination. For instance, Table 4 shows that mainstream NB and premium NB kids options gain more than the fair share. Still, non-kid options within the same quality tier at Sainsbury's (i.e. standard PL tier and mainstream NB) and the same brand type and quality tier at Asda (i.e. standard PL tier) gain more than their fair share. These demand switches result in a profit decrease for the retailer of $1.9 \%$ in Sainsbury's and even $11.4 \%$ in Asda (who offers a broader kids assortment under the standard PL tier).

We are unable to quantify the impact of eliminating the kids PL line in the other two tiers (economy and premium PL), since both options are not offered by Asda and Sainsbury's during our observation period. As such, we consider the effect of hypothetically including the kids PL line in these tiers. For the economy PL tier, benchmark setting comparisons reveal that the introduction of economy kids alternative in Sainsbury's strongly hurts retailer's incumbent kids offerings (all with a higher margin), irrespective of the brand-quality type, resulting in a profit decrease $-0.05 \%$. However, in Asda, this introduction mainly hurts standard PL kids options and results in a profit decrease $-0.23 \%$. Moreover, the introduction of the kids line in the premium PL tier leads to an overall profit decrease $-0.07 \%$ in Sainsbury's but profit increase $0.04 \%$ in Asda. In Sainsbury's, introduction of premium kids line hurts standard PLs, but also high margin mainstream, premium

\footnotetext{
${ }^{16}$ For the clarification, we only report the detailed kids line results for one retailer (Asda) in the Appendix. Detailed results tables for the health and muesli lines are available on request.
} 
NB kids and mainstream NB regular options because of their greater drawing power (Sethuraman 1995). However, in Asda, this introduction only hurts standard PL regular options.

Table 4: Overview of kids delisting/introduction

\begin{tabular}{cc|cc|cc|cc|cc|c}
\multicolumn{2}{c|}{ Sainsbury's } \\
\hline \hline \multicolumn{2}{c|}{ Economy PL } & \multicolumn{2}{c|}{ Standard PL } & \multicolumn{2}{c|}{ Premium PL } & \multicolumn{2}{c|}{ Mainstream NB } & \multicolumn{2}{c|}{ Premium NB } & Profit \\
\multicolumn{2}{c|}{ Kids } & Regular & Kids & Regular & Kids & Regular & Kids & Regular & Kids & Regular \\
\hline Introduce & $(=)$ & $(-)$ & $(=)$ & N.A. & $(=)$ & $(-)$ & $(=)$ & $(-)$ & $(=)$ & $-0.05 \%$ \\
N.A. & $(=)$ & Drop & $(=)$ & N.A. & $(=)$ & $(++)$ & $(++)$ & $(++)$ & $(=)$ & $-1.9 \%$ \\
N.A. & $(=)$ & $(-)$ & $(=)$ & Introduce & $(=)$ & $(--)$ & $(-)$ & $(-)$ & $(=)$ & $-0.07 \%$ \\
\hline \hline
\end{tabular}

\begin{tabular}{cc|cc|cc|cc|cc|c|}
\multicolumn{10}{c|}{ Asda } \\
\hline \hline \multicolumn{2}{c|}{ Economy PL } & \multicolumn{2}{c|}{ Standard PL } & \multicolumn{2}{c|}{ Premium PL } & \multicolumn{2}{c|}{ Mainstream NB } & \multicolumn{2}{c|}{ Premium NB } & Profit \\
\multicolumn{1}{c|}{ Kids } & Regular & Kids & Regular & Kids & Regular & Kids & Regular & Kids & Regular & \\
\hline Introduce & $(=)$ & $(-)$ & $(-)$ & N.A. & $(=)$ & $(=)$ & $(=)$ & $(=)$ & $(=)$ & $-0.23 \%$ \\
N.A. & $(=)$ & Drop & $(++)$ & N.A. & $(=)$ & $(++)$ & $(=)$ & $(++)$ & $(=)$ & $-11.4 \%$ \\
N.A. & $(=)$ & $(=)$ & $(-)$ & Introduce & $(=)$ & $(=)$ & $(=)$ & $(=)$ & $(=)$ & $+0.04 \%$ \\
\hline \hline
\end{tabular}

Notes: N.A. $=$ not available at the retailer; $(=)$ : (diversion ratio - fair share) $<0.5 ;(+): 0.5<$ (diversion ratio - fair share $)<1 ;(++)=($ diversion ratio - fair share $)>1 ;+$ and $-:$ net profit respectively increases or decreases due to the elimination/introduction.

Healthy line. When standard PL healthy brand variants are eliminated at Sainsbury's, the lost share is mainly captured the outside good $(36.39 \%)$, followed by brands from the standard nonhealth (16.20\%), premium NB non-health (14.06\%) and mainstream NB non-health categories (11.37\%). Similar patterns are observed for Asda, except that the outside good is the least attractive option (15.22\% compared to $36.39 \%$ ). This implies that the healthy standard PL at Sainsbury's is able to attract considerably more cereal sales from competing retailers. Within the retailer, a comparison with the benchmark setting shows that the standard PL healthy line cannibalizes its own regular options and, in the case of Sainsbury's (Asda) steal share from the mainstream NB healthy (premium NB regular) options (see Table 5). As a result, the elimination of a healthy standard PLs leads to a category profit decrease of $2.60 \%$ in Sainsbury's and $0.09 \%$ in Asda.

When the retailer's premium PL healthy line is eliminated (Table 5), we see that the standard non-healthy options and mainstream NB healthy options again gain more than in the proportional 
benchmark setting in Sainsbury's and only standard regular options gain more than fair shares in Asda. Overall, adopting a healthy line under premium PL tier leads to a category profit increase of $2.84 \%$ in Sainsbury's and $0.04 \%$ in Asda.

Table 5: Overview of health delisting/introduction

\begin{tabular}{cc|cc|cc|cc|cc|c|}
\multicolumn{10}{l|}{ Sainsbury's } \\
\hline \hline \multicolumn{2}{c|}{ Economy PL } & \multicolumn{2}{c|}{ Standard PL } & \multicolumn{2}{c|}{ Premium PL } & \multicolumn{2}{c|}{ Mainstream NB } & \multicolumn{2}{c|}{ Premium NB } & Profit \\
\multicolumn{2}{c|}{ Health } & Regular & Health & Regular & Health & Regular & Health & Regular & Health & Regular \\
\\
\hline Introduce & $(=)$ & $(=)$ & $(-)$ & $(=)$ & $(=)$ & $(=)$ & $(-)$ & $(=)$ & $(=)$ & $-0.04 \%$ \\
N.A. & $(=)$ & Drop & $(++)$ & $(=)$ & $(=)$ & $(+)$ & $(=)$ & $(=)$ & $(=)$ & $-2.60 \%$ \\
N.A. & $(=)$ & $(=)$ & $(++)$ & Drop & $(=)$ & $(++)$ & $(=)$ & $(=)$ & $(=)$ & $-2.84 \%$ \\
\hline \hline
\end{tabular}

\begin{tabular}{rl|cc|cc|cc|cc|c|}
\multicolumn{10}{c|}{ Asda } \\
\hline \hline \multicolumn{2}{c|}{ Economy PL } & \multicolumn{2}{c|}{ Standard PL } & \multicolumn{2}{c|}{ Premium PL } & \multicolumn{2}{c|}{ Mainstream NB } & \multicolumn{2}{c|}{ Premium NB } & Profit \\
Health & Regular & Health & Regular & Health & Regular & Health & Regular & Health & Regular & \\
\cline { 1 - 7 } Introduce & $(=)$ & $(=)$ & $(-)$ & $(=)$ & $(=)$ & $(=)$ & $(=)$ & $(=)$ & $(=)$ & $-0.07 \%$ \\
N.A. & $(=)$ & Drop & $(++)$ & $(=)$ & $(=)$ & $(=)$ & $(=)$ & $(=)$ & $(+)$ & $-0.09 \%$ \\
N.A. & $(=)$ & $(=)$ & $(++)$ & Drop & $(=)$ & $(=)$ & $(=)$ & $(=)$ & $(=)$ & $-0.04 \%$ \\
\hline \hline
\end{tabular}

Notes: N.A. $=$ not available at the retailer; $(=)$ : (diversion ratio - fair share) $<0.5 ;(+): 0.5<($ diversion ratio - fair share $)<1 ;(++)=($ diversion ratio - fair share $)>1 ;+$ and - : net profit respectively increases or decreases due to the elimination/introduction.

If we hypothetically introduce an economy health PL alternative, this introduction mainly hurts standard PL regular options in both retailers, and mainstream NB regular options in a small extent in Sainsbury's. This results in a category profit decrease of $0.04 \%$. and $0.07 \%$ in Sainsbury's and Asda.

Muesli line. When the muesli line is dropped from the economy PL tier, a comparison of diversion ratios with benchmark setting shows that consumers substitute to closest tier's muesli alternatives which is standard PL muesli line. We also find that non-muesli standard PL alternatives gain more than their proportional or fair share in Sainsbury's (see Table 6). This can be expected given their strong low-price focus. Although the muesli line under the economy PL tier is able to attract considerable consumer demand from competing retailers, offering muesli line under economy PL still leads to a category profit decrease of $0.5 \%$ in both retailers. 
Table 6: Overview of muesli delisting/introduction

Sainsbury's

\begin{tabular}{|c|c|c|c|c|c|c|c|c|c|c|}
\hline \multicolumn{2}{|c|}{ Economy PL } & \multicolumn{2}{|c|}{ Standard PL } & \multicolumn{2}{|c|}{ Premium PL } & \multicolumn{2}{|c|}{ Mainstream NB } & \multicolumn{2}{|c|}{ Premium NB } & \multirow[t]{2}{*}{ Profit } \\
\hline Muesli & Regular & Muesli & Regular & Muesli & Regular & Muesli & Regular & Muesli & Regular & \\
\hline Drop & $(=)$ & (+) & (+) & $(=)$ & $(=)$ & $(=)$ & $(=)$ & N.A. & $(=)$ & $+0.5 \%$ \\
\hline$(=)$ & $(=)$ & Drop & $(+)$ & $(++)$ & $(=)$ & $(+)$ & $(=)$ & N.A. & $(=)$ & $-0.3 \%$ \\
\hline$(=)$ & $(=)$ & $(+)$ & $(+)$ & Drop & $(=)$ & $(+)$ & $(=)$ & N.A. & $(=)$ & $-0.4 \%$ \\
\hline
\end{tabular}

\begin{tabular}{|c|c|c|c|c|c|c|c|c|c|c|}
\hline \multicolumn{2}{|c|}{ Economy PL } & \multicolumn{2}{|c|}{ Standard PL } & \multicolumn{2}{|c|}{ Premium PL } & \multicolumn{2}{|c|}{ Mainstream NB } & \multicolumn{2}{|c|}{ Premium NB } & \multirow{2}{*}{ Profit } \\
\hline Muesli & Regular & Muesli & Regular & Muesli & Regular & Muesli & Regular & Muesli & Regular & \\
\hline Drop & $(=)$ & $(++)$ & $(=)$ & $(=)$ & $(=)$ & $(=)$ & $(=)$ & N.A. & $(=)$ & $+0.5 \%$ \\
\hline$(=)$ & $(=)$ & Drop & $(+)$ & $(=)$ & $(=)$ & $(=)$ & $(=)$ & N.A. & $(+)$ & $+0.08 \%$ \\
\hline$(=)$ & $(=)$ & $(+)$ & $(=)$ & Drop & $(=)$ & $(=)$ & $(=)$ & N.A. & $(=)$ & $-0.02 \%$ \\
\hline
\end{tabular}

Notes: N.A. $=$ not available at the retailer; $(=)$ : (diversion ratio - fair share) $<0.5 ;(+): 0.5<($ diversion ratio - fair share $)<1 ;(++)=($ diversion ratio - fair share $)>1 ;+$ and - : net profit respectively increases or decreases due to the elimination/introduction.

Similarly, when standard PL tier muesli alternatives are delisted from the assortment (see Table 6), benchmark comparisons reveal that consumers mainly switch to the closest tiers' with muesli alternatives, which are premium PL and mainstream NB in Sainsbury's. However, some consumers prefer to stay in the standard PL tier and switch to standard regular options both in Asda and Sainsbury's. Overall, adopting a muesli line under a standard PL tier leads to a category profit increase of $0.3 \%$ in Sainsbury's and profit decrease $0.08 \%$ in Asda.

Moreover, when the muesli line is dropped from the premium PL tier (see Table 6), consumers again mainly switch to closest tiers muesli alternatives, which are standard PL and mainstream NB. However, standard PL non muesli options also gain some share in Sainsbury's. In total, irrespective of the cannibalization with the standard PL tier, the higher margin premium PL labels results again in a profit increase of $0.02 \%$ in Asda and $0.4 \%$ in Sainsbury's.

We can summarize the line extension based findings as follows: When a kids line is eliminated/introduced in any PL tier, consumer show overall a more or less loyal pattern to the attribute itself and switch to available incumbent kids options irrespective of the brand type (PL vs. 
$\mathrm{NB})$. In contrast, for the health attribute, the dominant behavior is to switch to regular options of standard PL since it is the closest tier in brand-quality type dimension or mainstream NB healthy options. And lastly, for the muesli attribute, the dominant behavior is to switch to standard PLs regardless of the presence of the attribute. Only at Sainsbury's, where between PL tier is less strong, consumers also switch to other available incumbent muesli options. In addition to this, we see that line extensions can be a win-win outcome for retailers since they lead higher profits despite cannibalization of incumbent sales. This mitigates the concern of Quelch and Kenny (1994) about cannibalization being a serious problem with line extensions (Kadiyali et al. 1998).

\section{Price changes}

Lastly, we consider the effect of adjustments in the price of PLs for each PL tier. As NBs are, in general, higher priced than PLs, the NB-PL price differential $[p(N B)-p(P L)]$ is positive (Sethuraman and Gielens 2014). In this respect, Hoch and Lodish (2001) advise retailers to maintain a large price gap between PLs (aggregated across tiers) and NBs as it leads to higher PL share by weaning consumers away from NBs. Pauwels and Srinivasan (2004) obtain similar findings, where they specifically focus on the standard PL tier. In contrast, if one focuses on profitability rather than sales or share, a large price gap between PLs and NBs is not necessarily desirable (Sethuraman and Raju 2012). In fact, if retailers close the objective and perceived quality gap between PLs and NBs, they can gain higher profits by also reducing the price gap (Raju, Sethuraman, and Dhar 1995; Sayman, Hoch, and Raju 2002). Moreover, Sethuraman and Raju (2012) state in a recent review paper that given the profitable outcomes of increasing the price of PLs, 'the price differential can be reduced to near zero?'. However, the price differential (NB vs. PL) cannot be too low or zero, as consumers still are willing to pay a premium for NB image, even if they perceive the PL to be equivalent (Sethuraman 2003; Applebaum, Gerstner and Naik 2003). 
Table 7: The impact of alternative price changes on net profit

\begin{tabular}{lcc|c|c} 
Scenario's & \multicolumn{2}{c}{ price increase by \% } & $\begin{array}{c}\text { Sainsbury's } \\
\text { Profit }\end{array}$ & $\begin{array}{c}\text { Asda } \\
\text { Profit }\end{array}$ \\
\hline \multirow{2}{*}{ Below Standard PL } & \multirow{2}{*}{ Economy PL } & $30 \%$ & $0.60 \%$ & $1.00 \%$ \\
& & $50 \%$ & $1.50 \%$ & $2.70 \%$ \\
\hline \multirow{2}{*}{ Below Premium PL } & \multirow{2}{*}{ Standard PL } & $10 \%$ & $7.20 \%$ & $3.90 \%$ \\
\hline Below Mainstream & \multirow{2}{*}{ Premium PL } & $10 \%$ & $13.10 \%$ & $8.50 \%$ \\
NB & & $28 \%$ & $2.10 \%$ & $15.10 \%$ \\
\hline Equal to Mainstream & \multirow{2}{*}{ Premium PL } & $13 \%$ & N.A. & $0.00 \%$ \\
NB & & $43 \%$ & $2.40 \%$ & $0.10 \%$ \\
\hline Above Mainstream & \multirow{2}{*}{ Premium PL } & $20 \%$ & N.A. & N.A. \\
NB & & $50 \%$ & $3.30 \%$ & N.A. \\
\hline Equal to Premium & \multirow{2}{*}{ Premium PL } & $27 \%$ & $4.10 \%$ & $0.20 \%$ \\
\hline NB & & & N.A. \\
\hline
\end{tabular}

Notes: N.A. $=$ not applicable scenarios for the retailer. \% price increases are determined by taking into account certain price thresholds. For example, 10\%, 30\% and 50\% price increase scenarios still makes the economy PL cheaper than standard PL.

In what follows, we explore the impact of decreasing the gap between standard PLs and mainstream NBs by increasing the price of standard PLs by $10 \%$ and $20 \%$. These price increases result in a demand drop for standard PLs, mainly in favor of mainstream and premium NBs, and the outside good. However, these price increases lead overall to a net category profit increase for both retailers. For instance, for Sainsbury's we observe a category profit increase of $7.2 \%$ and $13.1 \%$ and 8.5\% and $15.1 \%$ for Asda (see Table 7). Hence, both retailers and NB manufacturers gain from this standard PL price increase, as it leads to a demand shift to NBs accompanied by a profit lift for the retailer.

Furthermore, Sethuraman and Gielens (2014) state that little is known about how premium PLs should be priced. Retailers are generally advised to set prices of their premium PLs slightly above NBs prices (Kumar and Steenkamp 2007) or at parity (Millward Brown 2008). Items in the 
top tier of a supermarket's sub-brands are sometimes more expensive than the market leaders (World Trademark Review 2012). In our case, both retailers price their premium PLs below the NBs. As such, we conduct an experiment by increasing the price of premium PLs in order to decrease the price differential between premium PLs and NBs. Accordingly, we explore the following four scenario's: (i) Premium PL price $+10 \%$ (ii) Premium PL price equal to Mainstream NB price (i.e. $+13 \%$ for Sainsbury's and $+43 \%$ for Asda) (iii) Premium PL price above Mainstream NB price (i.e. $+20 \%$ for Sainsbury's and $+50 \%$ for Asda) and (iv) Premium PL price equal to Premium NB price (i.e. $+27 \%$ for Sainsbury's) ${ }^{17}$ (see Table 7 ). Although the price increase of premium PLs results in a demand loss for itself, it is mainly in favor of standard PL and mainstream NBs and premium NBs. Note that the premium PL changes at Asda are very minor, which is due to the very small number of SKU's (i.e. 3). Our results suggest that a retailer should price its premium PLs above the mainstream and even equal to premium NBs in order to improve its net category profits.

The above discussion considered the profit impact of a price increase or delisting, holding the rival prices fixed. In practice, one can also consider the profit impact when the rivals respond. As a robustness analysis, we consider counterfactuals where rivals respond by half of the initiated price increase. For example, if the original initiated scenario is increasing the price of economy PLs by $10 \%$, we also increase the price of all rivals (standard PL, premium PLs, mainstream and premium NBs) by $5 \%$. A similar robustness analysis is done for all scenarios and group of brands. The results show that if competitors react by also increasing their prices, the retailer is better off by earning even more profits (see Table A-2 in Appendix).

In addition, we explore the extreme case where PL tier price is increased to infinity which

\footnotetext{
${ }^{17}$ At Asda, mainstream NBs are, on average, priced above premium NBs (i.e. 3.63 vs. 3.45), so we dropped scenario 4 for Asda.
} 
equals to an elimination of the entire assortment flagged under a PL tier to identify who competes with whom (see Table 8). In line with Geyskens et al. (2010), the retailer's standard PL offerings benefit proportionately more from dropping the economy PL tier. Economy PL brand variants therefore clearly cannibalize the standard PL brand variants. Or in other words, providing an economy PL tier shifts consumer demand from the standard PL tier (and to a much smaller extent of premium PL tier in the case of Asda) to the economy alternatives. Still, the economy PL tier is able to attract considerable consumer demand from competing retailers, probably the hard discounters like Aldi \& Lidl (see Vroegrijk et al. 2013). However, in total, deleting the economy PLs leads to a category profit increase of $1.9 \%$ for Sainsbury's and even $2.8 \%$ for Asda. Similarly, when standard PLs are eliminated from the retailer's assortment, the retailer's premium PLs and mainstream NB (and to a smaller extent premium NB in the case of Asda) offerings benefit comparatively more from this elimination by attracting more than their benchmark share or fair share. Standard PL alternatives mainly compete with the mainstream NBs (same quality tier but different brand type) and premium PLs (higher quality tier but same brand type). This first indicates that standard PLs are doing what they are designed for, competing with the mainstream NBs (see Kumar and Steenkamp 2007), but at the small cost that part of the standard PL demand comes from the (higher margin) premium PL alternatives. In line with the economy PL tier, the standard PL tier considerably attracts demand from competing retailers. Overall, adopting a standard PL tier leads to a category profit increase of $11.9 \%$ for Sainsbury's and 18.3\% for Asda. Finally, when retailer's premium $P L$ options are eliminated, the economy PL option is clearly unattractive for premium PL buyers, whereas the standard PL tier and mainstream and premium NBs gain share. This indicates that premium PLs are cannibalizing the standard PL sales (partly supporting the findings of Geyskens et al. 2010), but not the economy PL sales. In this respect, Szymanowski and 
Gijsbrechts (2012) state that quality variation induced by the higher quality PL lines may dilute the signaling value of the standard PL brand. With regard to the economy tier, Palmeira and Thomas (2011) show that the quality perception of a value store brand (like the economy PL) are not affected by the presence of a premium store brand, which is supported by our findings. Irrespective of the cannibalization with the standard PL tier, the higher margin of premium PLs results in a profit increase of 3.3\% for Sainsbury's and $0.1 \%$ for Asda.

\begin{tabular}{|c|c|c|c|c|c|}
\hline $\begin{array}{c}\text { Sainsbury's } \\
\text { Economy } \\
\text { PLs }\end{array}$ & $\begin{array}{c}\text { Standard } \\
\text { PLs }\end{array}$ & $\begin{array}{c}\text { Premium } \\
\text { PLs }\end{array}$ & $\begin{array}{c}\text { Mainstream } \\
\text { NBs }\end{array}$ & $\begin{array}{c}\text { Premium } \\
\text { NBs }\end{array}$ & Profit \\
\hline $\begin{array}{c}\text { Infinite price } \\
\text { increase }\end{array}$ & $(++)$ & $=$ & $=$ & $=$ & \\
\hline$=$ & $\begin{array}{l}\text { Infinite price } \\
\text { increase }\end{array}$ & & $(++)$ & $=$ & $-11.90 \%$ \\
\hline$=$ & $(++)$ & $\begin{array}{c}\text { Infinite price } \\
\text { increase } \\
\end{array}$ & $=$ & $=$ & $-3.30 \%$ \\
\hline \multicolumn{6}{|l|}{ Asda } \\
\hline $\begin{array}{c}\text { Economy } \\
\text { PLs } \\
\end{array}$ & $\begin{array}{c}\text { Standard } \\
\text { PLs } \\
\end{array}$ & $\begin{array}{c}\text { Premium } \\
\text { PLs } \\
\end{array}$ & $\begin{array}{c}\text { Mainstream } \\
\mathrm{NBs} \\
\end{array}$ & $\begin{array}{c}\text { Premium } \\
\text { NBs } \\
\end{array}$ & Profit \\
\hline $\begin{array}{c}\text { Infinite price } \\
\text { increase }\end{array}$ & $(++)$ & $=$ & $=$ & $=$ & $2.80 \%$ \\
\hline$=$ & $\begin{array}{l}\text { Infinite price } \\
\text { increase }\end{array}$ & $=$ & $(++)$ & $=$ & $-18.30 \%$ \\
\hline$=$ & $(++)$ & $\begin{array}{c}\text { Infinite price } \\
\text { increase }\end{array}$ & & $=$ & $-0.10 \%$ \\
\hline
\end{tabular}

Table 8: Who competes with whom?

Notes: N.A. = not available at the retailer; $(=)$ : (diversion ratio - fair share) $<0.5 ;(+): 0.5<($ diversion ratio - fair share $)<1 ;(++)=($ diversion ratio - fair share $)>1 ;+$ and $-:$ net profit respectively increases or decreases due to the elimination/introduction.

Consistent with Sethuraman and Raju (2012) and ter Braak et al. (2013), who refer to premium PLs as the high-margin tier, our results also show that the presence of a premium PL tier contributes positively to the retailer's profitability. In the case of Asda, the impact of elimination of the premium PL tier is minor, which is due to the very low number of premium PL SKU's currently offered at the retailer. In sum, economy buyers switch mainly to the retailer's standard PL options, 
whereas standard and premium PL buyers mainly switch to each other as well as NB options. Overall, adopting an economy PL tier leads to a category profit decrease, however standard and premium PLs positively affects category profits.

Lastly, given that providing economy tier in the assortment does not generate additional profit in all levels (whole tier, line or brand variant), we experiment with the prices of the economy tier by increasing the price $10 \%, 30 \%$ and $50 \%$ to check whether without dropping the tier, any increase in the prices result in a profitable way (see Table 7). Our results also show that although the price increase of economy PLs results in a demand loss for itself mainly in favor of standard PL, mainstream and premium However, in total economy PL's price increase leads to a category profit increase of $0.6 \%, 1.5 \%$ and $2.3 \%$ for Sainsbury's and $1 \%, 2.7 \%$ and $3.9 \%$ for Asda respectively.

In brief, these price counterfactuals display that a PL price increase, irrespective of the tier, results in a further improvement of a retailer's category profits accompanied with an increased demand for the NB alternatives.

\section{Differences between retailers}

The above findings reveal some interesting differences between our two focal retailers, Sainsbury's and Asda. Overall, in the different scenarios, the competition between the different PL tiers and lines turns out to be stronger at Asda relative to Sainsbury's. This might be driven by the fact that the price gap between the three PL tiers is much smaller at Asda than at Sainsbury's. As indicated by Sethuraman (1995), cross-competitive effects are stronger when the price gap between two brands is smaller because the two brands will be more likely to enter a consumer's consideration set (see also Gielens 2012 for a similar reasoning in a new product introduction setting). 


\section{Discussion}

Worldwide, more and more retailers are carrying multiple PL tiers within a category. In fact, the importance (and number) of economy and premium PLs, next to the standard PLs, has increased as has a range of PL lines focusing on healthy eating, kids and organic foods (Planet Retail 2013). However, what are the implications of this ongoing PL proliferation into tiers and lines on competition between both PL and NB brand variants in a retailer's assortment, and subsequently on retailer's profits?

If we first explore the overall competition between PL tiers (irrespective of PL lines within a tier), our findings indicate that economy and premium PL tiers mainly cannibalize the standard PLs, which confirms prior insights (Geyskens et al. 2010). On top of this, our study reveals that standard PLs partly cannibalize premium PLs. Despite the cannibalization between PLs, all PL tiers are able to attract sales from competing retailers, and, except for the economy PLs, to ameliorate category profitability. Still, contrary to standard and premium PLs, the acquired low-priced economy PL sales, coming not only from competing retailers but form other (higher-priced) alternatives at the focal retailer, result in a less profitable situation. On top, our price simulation reveal that retailers can strengthen their category profitability by closing the price gap between their PL offerings and the NB alternatives. This strategy comes at a cost of losing PL sales but boosts more profitable NB sales. Interestingly, a retailer can uplift the profit generated by its economy tier by upgrading its price. Likewise, a retailer can further improve its profits by increasing the prices of its standard PL products, despite the switch of some of their standard PL buyers to mainstream and premium NBs. Similar, a price increase for the premium PL brand variants improves profits.

Overall, very similar patterns are observed with regard to $P L$ line extensions and deletions within a PL tier. All line extensions (i.e. kids, muesli and health) in the premium PL tier cannibalize 
standard PLs (but not the economy PLs) but, in contrary to the tier level, to also steal business from the mainstream and premium NBs with the same attribute (i.e. kids, muesli and health), resulting in a profitable outcome. Most standard PL line extensions (i.e. kids, muesli and health) again steal demand from own premium PLs (not economy PLs) but also from mainstream NBs and improve retailer's profitability. Only for the economy PLs, our findings indicate that at all levels (i.e. whole tier, line and brand variant) retailers do not earn additional profits with their low-priced offerings, questioning their excessively large assortment. However, for retailers pursuing objectives other than profit maximization, like generating store traffic or competing with hard discounters (see Vroegrijk et al. 2013), an appropriate strategy would be to simply reduce this tier's assortment, instead of dropping it altogether.

These findings are consistent with recent business practices. More and more retailers are (i) further proliferating their standard and premium PL assortment, and (ii) boosting the price of their economy PL alternatives. Firstly, U.S.’s third largest food retailing company Supervalu expanded its PL business in 2012 with another 1,500 new products of medium and premium quality, including a line of natural and organic foods called Wild Harvest (Market Watch 2012). Likewise, U.S. retailer Kroger has expanded its organic and healthy (standard and premium) PL lines recently (Market Watch 2012). According to a report of Food Product Design (2015), there is opportunity to increase category participation by introducing more premium product lines featuring organic, healthy products (Food Product Design 2015). This reasoning is supported by our findings that indicate that introducing a healthy line under the premium tier umbrella attracts considerable amount of share from competing retailers.

Secondly, there is an ongoing discussion in the grocery retailing whether introducing economy PLs is really a right strategy to fight with discounters and in the end the net effect of this strategy for 
the retailer is a big question mark in terms of profitability. Koen de Jong who is Managing Partner, International Private Label Consult (IPLC) claim that "many mainstream retailers have expanded or re-launched their economy PL lines to mitigate the risk of losing shoppers to discounters. However, we believe that negative effects may result from this strategy. Economy PLs generate lower margins

to retailers than NB equivalent PLs. As a result, offering economy PLs may lead to an erosion of category profitability due to cannibalizing effects". Indeed, the top grocery retailers in UK (i.e Tesco, Sainsbury's and Asda) have increased the price of more than 40 per cent on average of their economy PLs in the previous years given that rising commodity costs and food inflation put pressure on the profitability of the bottom line (Daily Mail 2013). Both Tesco and Sainsbury's indicate that despite price rises, their economy ranges are as popular as ever (Daily Mail 2012).

\section{Limitations and Further Research}

Our research has several limitations that offer interesting avenues for future research. First of all, our analysis focuses only on one FMCG category and two (leading) retailers, which prevents us to generalize our findings. Future research should study NB-PL competition across a large set of product categories but also within a large set of retailers, in order to generalize our findings, but especially to study moderating retailer and category effects. In this respect, ter Braak et al. (2014) already reveal that retailers introduce premium PLs in some categories but not in others.

Second, although the inclusion of the outside good in our model allows for flexible substitution towards other retailers' offerings, further insights are needed into which retailers attract these lost sales. For the economy PLs case, one can expect that consumer switch to offerings of hard discounters (like Aldi \& Lidl) and maybe economy PL offerings of competing traditional retailers as economy PLs are strategically introduced to fight with these alternatives (Dekimpe et al. 2011 and Vroegrijk et al. 2013). Likewise, with regard to for the standard and premium PLs, 
consumers might switch to traditional retailers' NBs, but also their standard and premium PL offerings. Hence, further research is called for the study this inter- and intra-tier completion not only within a retailer but across retailers, helping retailers in further mapping out their own PL strategy.

Third, in our counterfactual analysis, we held the prices of the rival alternatives at the retailer constant. In our sensitivity analysis, we already considered partial rival price responses to a price increase for a PL alternative, and we find even stronger profit effects. In reality, the prices of competing offerings might also increase as a reaction to an entirely new tier/line/brand variant delisting (and vice versa for the introduction of a new PL alternative). Future research should further study the net result of these simultaneous actions. 


\section{References}

Ailawadi, K. L., Pauwels, K., \& Steenkamp, J. B. E. (2008). Private-label use and store loyalty. Journal of Marketing, 72(6), 19-30.

Allenby, G. M., \& Rossi, P. E. (1991). Quality perceptions and asymmetric switching between brands. Marketing science, 10(3), 185-204.

Applebaum, E., Gerstner, E. , \& Naik, P. (2003), "The Effects of Expert Quality Evaluations vs. Brand Name on Price Premiums," Journal of Product and Brand Management,12 (3),15465.

Asda Supplier (2016). Asda Supplier. http://www.asdasupplier.com/about-us/about-asda (Retrieved 20 February 2016).

Bodapati, A. V., \& Gupta, S. (2005). Purchase-Frequency Bias in Random-Coefficients BrandChoice Models. Journal of Business \& Economic Statistics, 23(4), 473-484.

Bozhinova, M. (2014). Private label-retailers' competitive strategy. Global Journal of Management And Business Research, 13(10).

Burt, S. (2000). The strategic role of retail brands in British grocery retailing. European Journal of Marketing, 34(8), 875-890.

Chintagunta, P. K., \& Dube, J. P. (2005). Estimating a stock-keeping-unit-level brand choice model that combines household panel data and store data. Journal of Marketing Research, 42(3), 368-379.

Chib, S., Seetharaman, P. B., \& Strijnev, A. (2004). Model of brand choice with a no-purchase option calibrated to scanner-panel data. Journal of Marketing Research, 41(2), 184-196.

Chintagunta, P. K., Bonfrer, A., \& Song, I. (2002). Investigating the effects of store-brand introduction on retailer demand and pricing behavior. Management Science, 48(10), 12421267.

Chintagunta, P. K. (2002). Investigating category pricing behavior at a retail chain. Journal of Marketing Research, 39(2), 141-154.

Conlon, C. T., \& Mortimer, J. H. (2013). An experimental approach to merger evaluation (No. w19703). National Bureau of Economic Research.

Cotterill, R. W. (1997). The food distribution system of the future: convergence towards the US or UK model?. Agribusiness, 13(2), 123-135.

Daily Mail (2012). Families hit after supermarkets hike 'budget' food prices by as much as $110 \%$ in just a year. http://www.dailymail.co.uk/news/article-2249737/Families-hit-supermarketshike-budget-food-prices-110-just-year.html. (Retrieved May 12, 2015).

Daily Mail (2013). Tesco raises prices in its Everyday Value range by more than $50 \%$ despite huge Christmas sales boost. http://www.dailymail.co.uk/news/article-2260304/Tesco-raisesprices-Everyday-Value-range-50-despite-huge-Christmas-sales-boost.html. (Retrieved May 12, 2015).

Dekimpe, M. G., Gielens, K., Raju, J., \& Thomas, J. S. (2011). Strategic assortment decisions in information-intensive and turbulent environments. Journal of Retailing, 87, 17-28.

Empen, J., J.-P. Loy, and C. R. Weiss (2011). Price Promotions and Brand Loyalty: Empirical Evidence for the German Breakfast Cereals Market. Technical report.

Food Product Design (2015). Millennials Driving Private-Label Sector Growth. http://www.foodproductdesign.com/blogs/trending-foods/2015/03/millennials-drivingprivate-label-food-growth.aspx (Retrieved May 16, 2015). 
Geyskens, I., Gielens, K., \& Gijsbrechts, E. (2010). Proliferating private-label portfolios: how introducing economy and premium private labels influences brand choice. Journal of Marketing Research, 47(5), 791-807.

Gielens, K. (2012). New products: The antidote to private label growth?. Journal of Marketing Research, 49(3), 408-423.

Global Retail Mag (2013). Specialty Private Label Becomes A Premium Retail Brand. http://globalretailmag.com/index.php/specialty-private-label-becomes-a-premium-retailbrand/\#sthash.ACkOnBqJ.dpbs (Retrieved October 3, 2014).

Gordon, B. R., A. Goldfarb, and Y. Li (2013). Does Price Elasticity Vary with Economic Growth? A Cross-Category Analysis. Journal of Marketing Research, 50 (1), pp. 4-23.

Guadagni, P. M., and Little, J. D. C. (2008). A Logit Model of Brand Choice Calibrated on Scanner Data: A 25th Anniversary Perspective. Marketing Science, 27(1), 29-48.

Gupta, Sunil (1988), "Impact of Sales Promotions on When, What, and How Much to Buy," Journal of Marketing Research, 25 (November), 342-355.

Horsky, D., Pavlidis, P., \& Song, M. (2012). Incorporating state dependence in aggregate brandlevel demand models. Mimeo, University of Rochester.

Hoch, Stephen J. \& Lodish, L.M., (2001), “Store Brands and Category Management,” Working Paper, Wharton School, University of Pennsylvania.

IRI (2016). Private Label in Western Economies. Losing Share. https://www.iriworldwide.com/IRI/media/IRI-Clients/IRI-articlePDF/Private-Label-SpecialReport_Final-2.pdf (Retrieved October 16, 2016).

IRI (2015). Private Label in Western Economies. Closing the Price Gap, Losing Share. https://www.iriworldwide.com/IRI/media/IRI-Clients/PrivateLabel_report_final_7Jan15.pdf (Retrieved October 31, 2016).

IGD (2014). Private Label-Latest Research”, IGD Retail Analysis. http://retailanalysis.igd.com/Hub.aspx?id=102\&tid=9\&trid=9 (Retrieved May 5, 2014).

IPLG (2016). What Asda should do. http://us3.campaignarchive2.com/?u=dc81fb60f3daa5ecb5814da37\&id $=\mathrm{c} 3 \mathrm{fb} 122 \mathrm{~cd} 4 \& \mathrm{e}=\mathrm{c} 5 \mathrm{~d} 5 \mathrm{~d} 8 \mathrm{f} 6 \mathrm{f} 4$ (Retrieved November 3, 2016).

IPLG (2014). Private Labels in Europe. http://iplceurope.com/wpcontent/uploads/2014/02/seemarket.pdf (Retrieved November 16, 2014).

J Sainsbury plc (2016). Business Structure. http://www.j-sainsbury.co.uk/about-us/businessstructure/ (Retrieved March 21, 2016).

Just Food (2015). 7-Eleven launches premium private-label lines. http://www.just-food.com/news/7eleven-launches-premium-private-label-lines_id130438.aspx (Retrieved November 3, 2016).

Just Food (2013). Shopper Trends: Private-Label prices close in on brands. http://www.justfood.com/analysis/private-label-prices-close-in-on-brands_id124426.aspx (Retrieved October 27, 2016).

Kadiyali, V., Vilcassim, N., \& Chintagunta, P. (1998). Product line extensions and competitive market interactions: An empirical analysis. Journal of Econometrics, 89(1), 339-363.

Kalwani, Manohar U., Chi Kin Yim, Heikki J. Rinne and Yoshi Sugita (1990), "A Price Expectations Model of Customer Brand Choice," Journal of Marketing Research, 27 (August), 25 1-262.

Kelchtermans, S., \& Verboven, F. (2010). Program duplication in higher education is not necessarily bad. Journal of Public Economics, 94(5), 397-409. 
Kumar, N. and Steenkamp, J.E.M. (2007), Private Label Strategy: How to Meet the Store Brand Challenge, Harvard Business School Press, Boston (Massachusetts).

Lamey, L., Deleersnyder, B., Steenkamp, J. B. E., and Dekimpe, M. G. (2012). The effect of business-cycle fluctuations on private-label share: what has marketing conduct got to do with it?. Journal of Marketing, 76(1), 1-19.

Market Watch (2012). Kroger, conventional chains hop on organic private label bandwagon. http://newhope360.com/managing-your-business/kroger-conventional-chains-hop-organicprivate-label-bandwagon (Retrieved 10 January, 2015).

Melis, K., Campo, K., Breugelmans, E., and Lamey, L. (2015). The impact of the multi-channel retail mix on online store choice: Does online experience matter? Journal of Retailing.

Meza, S. and K. Sudhir (2010, September). Do private labels increase retailer bargaining power? Quantitative Marketing and Economics, 8 (3), 333-363.

Millward Brown (2008). What is in Store for Store Brands. http://www.millwardbrown.com/docs/default-source/insight-documents/points-ofview/millwardbrown_pov_whatsinstoreforbrands.pdf?sfvrsn=2 (Retrieved 11 February 2016).

Nevo, A. (2001). Measuring market power in the ready-to-eat cereal industry. Econometrica, 69 (2), pp. 307-342.

Nielsen (2014). The state of private label around the world.

http://www.nielsen.com/content/dam/nielsenglobal/kr/docs/global-

report/2014/Nielsen\%20Global\%20Private\%20Label\%20Report\%20November\%202014.pdf

(Retrieved September 19, 2016).

Quelch, J. A., \& Kenny, D. (1994). Extend profits, not product lines. Make Sure All Your Products Are Profitable, 14.

Palmeira, M. M., \& Thomas, D. (2011). Two-tier store brands: The benefic impact of a value brand on perceptions of a premium brand. Journal of Retailing, 87(4), 540-548.

Pauwels, K., Hanssens, D. M., \& Siddarth, S. (2002). The long-term effects of price promotions on category incidence, brand choice, and purchase quantity. Journal of marketing research, 39(4), 421-439.

Pauwels, K., \& Srinivasan, S. (2004). Who benefits from store brand entry? Marketing Science, 23(3), 364-390.

Petrin, A., \& Train, K. (2010). A control function approach to endogeneity in consumer choice models. Journal of Marketing Research, 47(1), 3-13.

Planet Retail (2013). Super Premium Private Labels in UK. (Retrieved April 13, 2015). http://www1.planetretail.net/news-and-events/rob-gregory/blogs/super-premium-privatelabels-uk .

PLMA (2016). Private Label Today. http://www.plmainternational.com/industry-news/private-labeltoday (Retrieved October 31, 2016).

PLMA (2011). Private Label Development, Toulouse School of Economics Newsletter. http://www.idei.fr/doc/nl/newsletter4_11_en.pdf (Retrieved November 25, 2014).

PWC (2011). The Private Labels Revolution. https://www.pwc.ru/ru/retail-consumer/assets/privatelabels-eng-may2011.pdf (Retrieved September 19, 2016).

Raju, J. S., Sethuraman, R., \& Dhar, S. K. (1995), "National Brand-Store Brand Price Differential and Store Brand Market Share," Pricing Strategy and Practice, 3(2), 17-24.

Sayman, Serdar, Stephen J. Hoch, and Jagmohan S. Raju (2002), "Positioning Store Brands," Marketing Science, 21 (Fall), 378-397. 
Sethuraman, Raj (2003), “Measuring National Brands' Equity over Store Brands," Review of Marketing Science, 1 (2), 1-26.

Seetharaman, P.B. (2004), "Modeling Multiple Sources of State Dependence in Random Utility Models: A Distributed Lag Approach,” Marketing Science, 23 (2), 263-71.

Sethuraman, R. (1995). A meta-analysis of national brand and store brand cross-promotional price elasticities. Marketing Letters, 6(4), 275-286.

Sethuraman, R., \& Gielens, K. (2014). Determinants of Store Brand Share. Journal of Retailing, 90(2), 141-153.

Sethuraman, R., \& Raju, J. S. (2012). 19 Private label strategies-myths and realities. Handbook of marketing strategy, 318.

Sethuraman, R., \& Raju, J. (2012). The Competition between National Brands and Store Brands: Models, Insights, Implications, and Future Research Directions. Foundations and Trends in Marketing, 7(1), 1-108.

Spotts, H. E. (Ed.). (2014). Assessing the Different Roles of Marketing Theory and Practice in the Jaws of Economic Uncertainty: Proceedings of the 2004 Academy of Marketing Science (AMS) Annual Conference. Springer.

Steenkamp, J. B. E., \& Geyskens, I. (2014). Manufacturer and retailer strategies to impact store brand share: Global integration, local adaptation, and worldwide learning. Marketing Science, 33(1), 6-26.

Szymanowski, M., \& Gijsbrechts, E. (2012). Consumption-based cross-brand learning: Are private labels really private?. Journal of Marketing Research,49(2), 231-246.

Tan, L. P., \& Cadeaux, J. (2011). Brand and stock-keeping-unit (SKU) assortments, assortment changes and category sales. The International Review of Retail, Distribution and Consumer Research, 21(2), 161-185.

Tarziján, J. (2003). Private labels and retail market concentration. Abante, 6(1), 1-20.

Ter Braak, A., Dekimpe, M. G., \& Geyskens, I. (2013). Retailer private-label margins: The role of supplier and quality-tier differentiation. Journal of Marketing, 77(4), 86-103.

Ter Braak, A., Geyskens, I., \& Dekimpe, M. G. (2014). Taking private labels upmarket: Empirical generalizations on category drivers of premium private label introductions. Journal of Retailing, 90(2), 125-140.

The Guardian (2013). Sainsbury's outperforms Tesco as sales growth continues. http://www.theguardian.com/business/2013/jun/12/sainsburys-outperforms-tesco-salesgrowth-continues (Retrieved January 21, 2015).

The Grocer (2014). Own Label Category Report. http://www.thegrocer.co.uk/reports/categoryreports/own-label-category-report-2014/356584.article (Retrieved February 16, 2016).

Train, K. (2003). Discrete Choice Models with Simulation. Cambridge University Press, Cambridge.

Ülger, B. (2008). Packages with cartoon trade characters versus advertising: an empirical examination of preschoolers' food preferences. Journal of Food Products Marketing, 15(1), 104-117.

Villas-Boas, J. M., \& Winer, R. S. (1999). Endogeneity in brand choice models. Management Science, 45(10), 1324-1338.

Vroegrijk, M., Gijsbrechts, E., \& Campo, K. (2013). Close encounter with the hard discounter: A multiple-store shopping perspective on the impact of local hard-discounter entry. Journal of Marketing Research, 50(5), 606-626.

Werden, G. J. (1998). Demand elasticities in antitrust analysis. Antitrust Law Journal, 66(2), 363- 
414.

World Trade Mark Review (2012). The-private label predicament. http://www.worldtrademarkreview.com/Magazine/Issue/39/Features/The-private-labelpredicament (Retrieved 12 February 2016).

YouGov (2013). Breakfast habits weekdays vs. weekends. https://yougov.co.uk/news/2013/07/23/breakfast-habits-weekdays-vs-weekend/ (Retrieved April 13, 2015). 
Table 2: Sainsbury's Estimation Results

\begin{tabular}{|c|c|c|c|c|c|c|c|}
\hline \multirow[b]{2}{*}{ Variables } & \multirow[b]{2}{*}{ Mean } & \multirow[b]{2}{*}{ Std. dev } & \multicolumn{5}{|c|}{ Interactions with household characteristics } \\
\hline & & & \# of children & Low class & Middle class & Buying Frequency & SoW \\
\hline Price & $\begin{array}{c}-1.081 * * * \\
(0.0424)\end{array}$ & $\begin{array}{c}0.534 * * * \\
(0.0109)\end{array}$ & $\begin{array}{c}0.0552 * * * \\
(0.0140)\end{array}$ & $\begin{array}{c}-0.159 * * * \\
(0.0386)\end{array}$ & $\begin{array}{c}-0.113 * * * \\
(0.0311)\end{array}$ & $\begin{array}{c}-0.00273 \\
(0.00459)\end{array}$ & $\begin{array}{c}0.197 * * * \\
(0.0358)\end{array}$ \\
\hline Outside Good & $\begin{array}{c}7.513 * * * \\
(0.161)\end{array}$ & $\begin{array}{c}2.888 * * * \\
(0.0642)\end{array}$ & & & & & \\
\hline Assortment & $\begin{array}{c}0.0854 * * * \\
(0.0103)\end{array}$ & & & & & & \\
\hline Loyalty & $\begin{array}{c}11.93 * * * \\
(0.0583)\end{array}$ & & & & & & \\
\hline \multicolumn{8}{|l|}{ Lines } \\
\hline Kids & & & $\begin{array}{c}0.327 * * * \\
(0.0146)\end{array}$ & $\begin{array}{l}0.129 * * \\
(0.0505)\end{array}$ & $\begin{array}{c}0.0943 * * \\
(0.0398)\end{array}$ & $\begin{array}{c}-0.0514 * * * \\
(0.00885)\end{array}$ & $\begin{array}{c}0.0354 \\
(0.0648)\end{array}$ \\
\hline Health & & & $\begin{array}{c}-0.220 * * * \\
(0.0161)\end{array}$ & $\begin{array}{c}-0.128 * * * \\
(0.0455)\end{array}$ & $\begin{array}{c}0.0139 \\
(0.0349)\end{array}$ & $\begin{array}{c}-0.0155^{* *} \\
(0.00780)\end{array}$ & $\begin{array}{c}-0.177 * * * \\
(0.0586)\end{array}$ \\
\hline Muesli & & & $\begin{array}{c}-0.137 * * * \\
(0.0294)\end{array}$ & $\begin{array}{c}-0.317 * * * \\
(0.0804)\end{array}$ & $\begin{array}{c}-0.0865 \\
(0.0589)\end{array}$ & $\begin{array}{c}0.00788 \\
(0.0128)\end{array}$ & $\begin{array}{c}0.474 * * * \\
(0.103)\end{array}$ \\
\hline \multicolumn{8}{|l|}{ Brand type vs. quality tiers } \\
\hline Economy PL & & & $\begin{array}{c}-0.294 * * * \\
(0.0876)\end{array}$ & $\begin{array}{c}0.973 * * * \\
(0.214)\end{array}$ & $\begin{array}{c}0.237 \\
(0.145)\end{array}$ & $\begin{array}{c}0.126 * * * \\
(0.0198)\end{array}$ & $\begin{array}{c}3.015 * * * \\
(0.150)\end{array}$ \\
\hline Standard PL & & & $\begin{array}{c}-0.268 * * * \\
(0.0772)\end{array}$ & $\begin{array}{c}0.528 * * * \\
(0.193)\end{array}$ & $\begin{array}{l}0.0521 \\
(0.126)\end{array}$ & $\begin{array}{l}0.0306 * \\
(0.0166)\end{array}$ & $\begin{array}{c}3.652 * * * \\
(0.116)\end{array}$ \\
\hline Premium PL & & & $\begin{array}{c}-0.466 * * * \\
(0.0863)\end{array}$ & $\begin{array}{c}0.525^{* *} \\
(0.219)\end{array}$ & $\begin{array}{c}0.134 \\
(0.149)\end{array}$ & $\begin{array}{c}0.0332 \\
(0.0240)\end{array}$ & $\begin{array}{c}3.445 * * * \\
(0.179)\end{array}$ \\
\hline Mainstream NB & & & $\begin{array}{c}-0.175 * * \\
(0.0792)\end{array}$ & $\begin{array}{c}0.539 * * * \\
(0.205)\end{array}$ & $\begin{array}{l}0.0479 \\
(0.137)\end{array}$ & $\begin{array}{c}0.0542 * * * \\
(0.0198)\end{array}$ & $\begin{array}{c}3.323 * * * \\
(0.148)\end{array}$ \\
\hline Premium NB & & & $\begin{array}{c}-0.382 * * * \\
(0.0793)\end{array}$ & $\begin{array}{c}0.572 * * * \\
(0.204)\end{array}$ & $\begin{array}{c}0.141 \\
(0.137)\end{array}$ & $\begin{array}{c}0.0413 * * \\
(0.0200)\end{array}$ & $\begin{array}{c}3.541 * * * \\
(0.145)\end{array}$ \\
\hline $\begin{array}{l}\text { Brand Variant Dummies } \\
* * * \mathrm{p}<0.01, * * \mathrm{p}<0.05, * \mathrm{p}<0.1\end{array}$ & Yes & & & & & & \\
\hline
\end{tabular}


Table 3: Asda Estimation Results

\begin{tabular}{|c|c|c|c|c|c|c|c|}
\hline \multirow[b]{2}{*}{ Variables } & \multirow[b]{2}{*}{ Mean } & \multirow[b]{2}{*}{ Std. dev } & \multicolumn{5}{|c|}{ Interactions with household characteristics } \\
\hline & & & \# of children & Low class & Middle class & Buying Frequency & SoW \\
\hline Price & $\begin{array}{c}-0.982 * * * \\
(0.0409)\end{array}$ & $\begin{array}{l}0.614 * * * \\
(0.0107)\end{array}$ & $\begin{array}{c}0.0990 * * * \\
(0.00968)\end{array}$ & $\begin{array}{l}-0.00670 \\
(0.0354)\end{array}$ & $\begin{array}{l}0.0518 \\
(0.0320)\end{array}$ & $\begin{array}{c}0.0166 * * * \\
(0.00336)\end{array}$ & $\begin{array}{c}-0.0716^{* *} \\
(0.0319)\end{array}$ \\
\hline Outside Good & $\begin{array}{c}7.479 * * * \\
(0.153)\end{array}$ & $\begin{array}{l}3.024 * * * \\
(0.0487)\end{array}$ & & & & & \\
\hline Assortment & $\begin{array}{c}0.0626 * * * \\
(0.00928)\end{array}$ & & & & & & \\
\hline Loyalty & $\begin{array}{l}11.65 * * * \\
(0.0492)\end{array}$ & & & & & & \\
\hline Lines & & & $0.278 * * *$ & $0.340 * * *$ & $0.147 * * *$ & 0.00132 & $0.183 * * *$ \\
\hline Kids & & & $(0.0101)$ & $(0.0383)$ & $(0.0338)$ & $(0.00504)$ & $(0.0488)$ \\
\hline Health & & & $\begin{array}{c}-0.206^{* * * *} \\
(0.0149)\end{array}$ & $\begin{array}{c}-0.127 * * * \\
(0.0486)\end{array}$ & $\begin{array}{c}-0.186 * * * \\
(0.0423)\end{array}$ & $\begin{array}{c}-0.0270 * * * \\
(0.00721)\end{array}$ & $\begin{array}{c}0.274 * * * \\
(0.0652)\end{array}$ \\
\hline Muesli & & & $\begin{array}{c}-0.157 * * * \\
(0.0245)\end{array}$ & $\begin{array}{l}-0.0471 \\
(0.0798)\end{array}$ & $\begin{array}{l}-0.0174 \\
(0.0684)\end{array}$ & $\begin{array}{c}-0.00520 \\
(0.0110)\end{array}$ & $\begin{array}{l}-0.0651 \\
(0.101)\end{array}$ \\
\hline Brand type vs. quality tiers & & & & & & & \\
\hline Economy PL & & & $\begin{array}{c}-0.247 * * * \\
(0.0413)\end{array}$ & $\begin{array}{c}0.538 * * * \\
(0.155)\end{array}$ & $\begin{array}{l}0.445 * * * \\
(0.139)\end{array}$ & $\begin{array}{l}0.0205 \\
(0.0133)\end{array}$ & $\begin{array}{c}4.333 * * * \\
(0.116)\end{array}$ \\
\hline Standard PL & & & $\begin{array}{c}-0.362 * * * \\
(0.0401)\end{array}$ & $\begin{array}{r}0.107 \\
(0.149)\end{array}$ & $\begin{array}{l}0.260^{*} \\
(0.133)\end{array}$ & $\begin{array}{l}0.00906 \\
(0.0121)\end{array}$ & $\begin{array}{c}4.526^{* * * *} \\
(0.103)\end{array}$ \\
\hline Premium PL & & & $\begin{array}{c}-0.627 * * * \\
(0.0851)\end{array}$ & $\begin{array}{l}-0.0601 \\
(0.268)\end{array}$ & $\begin{array}{c}0.123 \\
(0.226)\end{array}$ & $\begin{array}{l}0.0226 \\
(0.0320)\end{array}$ & $\begin{array}{c}3.872 * * * \\
(0.308)\end{array}$ \\
\hline Mainstream NB & & & $\begin{array}{c}-0.384 * * * \\
(0.0428)\end{array}$ & $\begin{array}{l}0.323 * * \\
(0.159)\end{array}$ & $\begin{array}{l}0.416^{* * * *} \\
(0.142)\end{array}$ & $\begin{array}{c}-0.0424 * * * \\
(0.0142)\end{array}$ & $\begin{array}{l}4.536 * * * \\
(0.126)\end{array}$ \\
\hline Premium NB & & & $\begin{array}{c}-0.514 * * * \\
(0.0423)\end{array}$ & $\begin{array}{c}0.242 \\
(0.157)\end{array}$ & $\begin{array}{c}0.353^{* *} \\
(0.140)\end{array}$ & $\begin{array}{c}-0.0759 * * * \\
(0.0139)\end{array}$ & $\begin{array}{l}4.721 * * * \\
(0.121)\end{array}$ \\
\hline $\begin{array}{l}\text { Brand Variant Dummies } \\
* * * \mathrm{p}<0.01, * * \mathrm{p}<0.05, * \mathrm{p}<0.1\end{array}$ & Yes & & & & & & \\
\hline
\end{tabular}




\section{APPENDIX}

Table A-1: Introducing/Delisting Kids Lines from the Tiers (Asda)

\begin{tabular}{|c|c|c|c|c|c|c|c|c|c|c|c|c|}
\hline & \multicolumn{2}{|c|}{ Economy PL } & \multicolumn{2}{|c|}{ Standard PL } & \multicolumn{2}{|c|}{ Premium PL } & \multicolumn{2}{|c|}{ Mainstream NB } & \multicolumn{2}{|c|}{ Premium NB } & \multirow[t]{2}{*}{$\begin{array}{l}\text { Outside } \\
\text { Good }\end{array}$} & \multirow[t]{2}{*}{$\begin{array}{c}\text { Net } \\
\text { Profit }\end{array}$} \\
\hline & Kids & $\begin{array}{l}\text { Non- } \\
\text { kids }\end{array}$ & Kids & $\begin{array}{l}\text { Non- } \\
\text { Kids }\end{array}$ & Kids & $\begin{array}{l}\text { Non- } \\
\text { Kids }\end{array}$ & Kids & Non-Kids & Kids & Non-Kids & & \\
\hline $\begin{array}{l}\text { Diversion Ratio } \\
\text { Full Model }\end{array}$ & Introduce & $4.3 \%$ & $15.6 \%$ & $17.0 \%$ & N.A. & $0.3 \%$ & $4.3 \%$ & $16.7 \%$ & $8.2 \%$ & $17.4 \%$ & $16.2 \%$ & \\
\hline $\begin{array}{l}\text { Inside Good DR } \\
\text { Full Model }\end{array}$ & Introduce & $5.1 \%$ & $18.6 \%$ & $20.2 \%$ & N.A. & $0.4 \%$ & $5.2 \%$ & $19.9 \%$ & $9.8 \%$ & $20.8 \%$ & & \\
\hline $\begin{array}{l}\text { Inside Good DR } \\
\text { Benchmark }\end{array}$ & Introduce & $6.6 \%$ & $17.0 \%$ & $18.0 \%$ & N.A. & $0.4 \%$ & $5.2 \%$ & $21.0 \%$ & $9.4 \%$ & $22.5 \%$ & & \\
\hline$\Delta$ Profit & $0.1 \%$ & $0.0 \%$ & $-0.1 \%$ & $-0.1 \%$ & N.A. & $0.0 \%$ & $0.0 \%$ & $-0.1 \%$ & $0.0 \%$ & $-0.1 \%$ & & $-0.23 \%$ \\
\hline $\begin{array}{l}\text { Diversion Ratio } \\
\text { Full Model }\end{array}$ & N.A. & $4.6 \%$ & Drop & $18.3 \%$ & N.A. & $0.3 \%$ & $5.8 \%$ & $18.8 \%$ & $9.9 \%$ & $17.9 \%$ & $24.3 \%$ & \\
\hline $\begin{array}{l}\text { Inside Good DR } \\
\text { Full Model }\end{array}$ & N.A. & $6.1 \%$ & Drop & $24.2 \%$ & N.A. & $0.5 \%$ & $7.6 \%$ & $24.9 \%$ & $13.1 \%$ & $23.7 \%$ & & \\
\hline $\begin{array}{l}\text { Inside Good DR } \\
\text { Benchmark }\end{array}$ & N.A. & $7.9 \%$ & Drop & $21.7 \%$ & N.A. & $0.5 \%$ & $6.2 \%$ & $25.3 \%$ & $11.3 \%$ & $27.1 \%$ & & \\
\hline$\Delta$ Profit & N.A. & $0.2 \%$ & $-23.7 \%$ & $3.1 \%$ & N.A. & $0.1 \%$ & $1.1 \%$ & $3.3 \%$ & $1.7 \%$ & $2.9 \%$ & & $-11.4 \%$ \\
\hline $\begin{array}{l}\text { Diversion Ratio } \\
\text { Full Model }\end{array}$ & N.A. & $3.91 \%$ & $12.90 \%$ & $15.71 \%$ & Introduce & $0.49 \%$ & $3.80 \%$ & $15.49 \%$ & $6.93 \%$ & $15.90 \%$ & $24.87 \%$ & \\
\hline $\begin{array}{l}\text { Inside Good DR } \\
\text { Full Model }\end{array}$ & N.A. & $5.20 \%$ & $17.17 \%$ & $20.92 \%$ & Introduce & $0.65 \%$ & $5.06 \%$ & $20.62 \%$ & $9.22 \%$ & $21.16 \%$ & & \\
\hline $\begin{array}{l}\text { Inside Good DR } \\
\text { Benchmark }\end{array}$ & N.A. & $6.61 \%$ & $16.85 \%$ & $17.91 \%$ & Introduce & $0.47 \%$ & $5.32 \%$ & $21.50 \%$ & $9.26 \%$ & $22.08 \%$ & & \\
\hline$\Delta$ Profit & N.A. & $0.00 \%$ & $-0.01 \%$ & $-0.01 \%$ & $0.09 \%$ & $0.00 \%$ & $0.00 \%$ & $-0.01 \%$ & $0.00 \%$ & $-0.01 \%$ & & $+0.04 \%$ \\
\hline
\end{tabular}


Table A-2: Sainsbury's and Asda net category profits by including competitors' reactions

\begin{tabular}{|c|c|c|c|c|}
\hline Scenario's & price incr & by $\%$ & $\begin{array}{c}\text { Sainsbury's } \\
\text { Profit } \\
\end{array}$ & $\begin{array}{l}\text { Asda } \\
\text { Profit }\end{array}$ \\
\hline Below Standard PL & $\begin{array}{c}\text { Economy } \\
\text { PL }\end{array}$ & $\begin{array}{l}10 \% \\
30 \% \\
50 \%\end{array}$ & $\begin{array}{l}\text { (+) } 18 \% \\
(+) 52 \% \\
(+) 82 \%\end{array}$ & $\begin{array}{l}\text { (+) } 18 \% \\
(+) 51 \% \\
(+) 79 \%\end{array}$ \\
\hline Below Premium PL & $\begin{array}{c}\text { Standard } \\
\text { PL }\end{array}$ & $\begin{array}{l}10 \% \\
20 \% \\
\end{array}$ & $\begin{array}{l}+(+) 22 \% \\
(+) 42 \% \\
\end{array}$ & $\begin{array}{l}+(+) 22 \% \\
(+) 42 \% \\
\end{array}$ \\
\hline Below Mainstream NB & $\begin{array}{l}\text { Premium } \\
\text { PL }\end{array}$ & $\begin{array}{l}10 \% \\
28 \% \\
\end{array}$ & $\begin{array}{c}(+) 22 \% \\
\text { N.A. }\end{array}$ & $\begin{array}{l}\text { (+) } 19 \% \\
\text { (+) } 47 \% \\
\end{array}$ \\
\hline Equal to Mainstream NB & $\begin{array}{l}\text { Premium } \\
\text { PL }\end{array}$ & $\begin{array}{l}13 \% \\
43 \% \\
\end{array}$ & $\begin{array}{c}(+) 25 \% \\
\text { N.A. }\end{array}$ & $\begin{array}{c}\text { N.A. } \\
\text { (+) } 68 \% \\
\end{array}$ \\
\hline Above Mainstream NB & $\begin{array}{l}\text { Premium } \\
\text { PL }\end{array}$ & $\begin{array}{l}20 \% \\
50 \%\end{array}$ & $\begin{array}{c}(+) 47 \% \\
\text { N.A. }\end{array}$ & $\begin{array}{c}\text { N.A. } \\
(+) 83 \%\end{array}$ \\
\hline Equal to Premium NB & $\begin{array}{l}\text { Premium } \\
\text { PL }\end{array}$ & $27 \%$ & (+) $51 \%$ & N.A. \\
\hline
\end{tabular}

Note: Sainsbury's and Asda's net category profit changes are calculated by taking into account competitors' price response. We assume that competitors also increase their prices by half of the original brand's price change (e.g. if price of the economy PL is changed by $10 \%$, competitors react by changing their prices $5 \%$ ).

\section{A-3 Derivation of choice probabilities}

Assume that household $i$ chooses the brand variant $j$ that maximizes utility among all the available alternatives, conditional on household $i$ 's available choice set. Then the probability that household $i$ chooses brand variant $j$ is given by:

$$
\operatorname{Pr}_{i j}\left(v_{i}\right)=\frac{\exp \left(\gamma_{i j}+\beta_{i} X_{j t}+\alpha_{i} p_{j t}+\theta_{i} I_{i j t}+\xi_{j t}\right)}{1+\sum_{k=1}^{J} \exp \left(\gamma_{i k}+\beta_{i} X_{k t}+\alpha_{i} p_{k t}+\theta_{i} I_{i k t}+\xi_{j t}\right)}
$$

With unobserved heterogeneity, it is necessary to integrate the conditional choice probability $\operatorname{Pr}_{i j}$ over the unobserved individual term $v_{i}$ (containing the unobserved individual-specific valuation of price and the outside good, as discussed in the text). Then, we obtain the random coefficients logit choice probability: 


$$
s_{i j}=\int_{v} \operatorname{Pr}_{i j}\left(\text { HHchar }, v_{i}\right) d F\left(\text { HHchar }, v_{i}\right)
$$

Following Train (2003), to approximate the integral in (2), we take $R$ draws for $v_{i}$ from the standard normal distribution to obtain average choice probability for each household:

$$
\begin{aligned}
& s_{i j} \\
& =\frac{1}{R} \sum_{r=1}^{R} \frac{\exp \left(\gamma_{j}^{0}+\beta_{i} X_{j}+\theta_{i} I_{i j}-\left(\alpha^{0}+\sigma v_{i}^{r}\right) p_{i j}+\left(P G d u m m y_{p}, p_{i j}\right) \Pi H H c h a r_{i}\right)}{1+\sum_{k=1}^{J} \exp \left(\gamma_{k}^{0}+\beta_{i} X_{k}+\theta_{i} I_{i k}-\left(\alpha^{0}+\sigma v_{i}^{r}\right) p_{i k}+\left(P G d u m m y_{p}, p_{i k}\right) \Pi H H c h a r\right.}
\end{aligned}
$$

where $\Pi$ denotes the matrix of parameters capturing the impact of household characteristics on the valuation for the product group dummies $P G d u m m y_{p}$ and price $p_{i j}$ (as it denotes $\gamma^{h p}$ and $\left.\alpha^{h}\right)$. To estimate the parameters we use the method of simulated maximum likelihood, where the choice probabilities (3) form the basis for the likelihood function. 